\title{
Contribución al conocimiento de la flora del Santuario de la Naturaleza Serranía El Ciprés, Región de Valparaíso, Chile
}

\section{Contribution to the knowledge of the flora of "Serranía El Ciprés" Nature Sanctuary, Valparaíso Region, Chile}

\author{
Andrés Madrid ${ }^{1 *}$, Juan Larraín ${ }^{2}$, Jorge Macaya ${ }^{3} \&$ Sebastián Teillier ${ }^{4}$ \\ ${ }^{1}$ Consultor independiente. Los Militares 5953, Of. 801, Santiago, Chile. \\ ${ }^{2}$ Consultor independiente. Las Palmas S/N, Olmué, Chile. \\ ${ }^{3}$ Cedrem Consultores. Padre Mariano 82, Of. 1003, Santiago, Chile. \\ ${ }^{4}$ Escuela de Arquitectura del Paisaje, Universidad Central de Chile. Santa Isabel 1186, Santiago, Chile. \\ *andresmadridp@gmail.com
}

\begin{abstract}
RESUMEN
El Santuario de la Naturaleza "Serranía El Ciprés” es un sitio prioritario para la conservación de la biodiversidad al nivel regional y nacional en Chile. Se ubica administrativamente en la Región de Valparaíso, en la ecorregión mediterránea. El objetivo de este trabajo es estudiar la riqueza y la composición de su flora vascular. Los resultados indican que en el área existen al menos 297 taxa, pertenecientes a 293 especies, 183 géneros y 74 familias. Las familias mejor representadas son Asteraceae, Fabaceae y Poaceae. La riqueza de especies en relación con la superficie es mayor a la esperada en Chile central (226-272), donde 272 (92,8\%) son nativas, de las que 145 (53,3\%) son endémicas de Chile y 21 (7,2\%), alóctonas asilvestradas. Las formas de vida de Raunkiaer predominantes fueron las hemicriptófitas (26,4\%), las terófitas (23,5\%) y las caméfitas (17,7\%). Se encontraron diez especies clasificadas oficialmente en alguna categoría de conservación, cinco de ellas como "vulnerable", ellas son Citronella mucronata, Eriosyce aurata, Placea ornata, Porlieria chilensis y Prosopis chilensis. Se registran, además, siete especies nuevas para la Región.
\end{abstract}

Palabras Clave: Flora de Chile, riqueza, composición, endemismo, Austrocedrus.

\begin{abstract}
The Nature Sanctuary "Serranía El Ciprés" is considered as a hotspot for the conservation of biodiversity at regional and national level in Chile. It is located administratively in the Valparaiso Region. in the Mediterranean eco-region. The objective of this work is to study the richness and composition of its vascular flora. The results indicate that there are at least 297 taxa in the area, belonging to 293 species, 183 genera and 74 families. The best represented families are Asteraceae, Fabaceae and Poaceae. The species richness in relation to the area is greater than expected in central Chile (226-272), where 272 (92.8\%) are native, of which $145(53.3 \%)$ are endemic to Chile and 21 (7.2\%) are foreign. The predominant Raunkiaer life forms were hemicryptophytes $(26.4 \%)$, terophytes $(23.5 \%)$ and camephytes $(17.7 \%)$. Ten species were officially classified in some categories of conservation, five of them as "vulnerable", they are Citronella mucronata, Eriosyce aurata, Placea ornata, Porlieria chilensis and Prosopis chilensis. There are also seven new species for the Region.
\end{abstract}

KeYwords: Flora of Chile, richness, composition, endemism, Austrocedrus.

\section{INTRODUCCIÓN}

Las ecorregiones mediterráeas se destacan por su riqueza y elevada proporción de especies endémicas. Para el caso de Chile central, parte de dicha ecorregión, se ha sugerido que la riqueza de la flora alcanza a unas 2500 especies, con un grado de endemismo regional cercano al 23\% (Cowling et al. 1996; Arroyo \& Cavieres 1997). Esta zona es, también, la más poblada de Chile, por lo que carga con una larga historia de intervención y reemplazo de sus ecosistemas naturales (Cunill 1970; Aschmann \& Bahre 1977; Fuentes \& Hajek 1979). Esta combinación de un alto grado de endemismo y riqueza, con una intensa y extensa intervención antrópica, ha llevado a que a la región se le considere como un hotspot para la conservación de la biodiversidad a nivel mundial (Arroyo et al. 1999; Myers et al. 2000). 
De acuerdo con Di Castri \& Hajek (1976), el Santuario de la Naturaleza Serranía El Ciprés se encuentra bajo la influencia de un clima mediterráneo árido, en su límite meridional, lo que implica que se trata de una zona transicional con el clima mediterráneo semiárido, aumentando la tendencia hacia un clima eumediterráneo. La humedad, muy elevada en la costa, se reduce considerablemente hacia el interior, donde se registra, a la vez, un notable incremento de la amplitud térmica diaria y anual, con evolución hacia un leve continentalismo. En términos topográficos, el área incluye por el norte al cerro Tabaco (2.342 m s.n.m.), su cumbre más alta; por el oeste, a los cerros Botija (2.110 m s.n.m.) y Puerta del Alto (2.193 m s.n.m.); por el sur, los cerros Las Cabras (1.830 m s.n.m.) y Lomas Renca (1684 m s.n.m.); y por el noreste, el cerro Bruno (2.196 m s.n.m.) y los faldeos del cerro Las Bateas (1.334 m s.n.m.). La parte más baja del Santuario se encuentra a unos $1.000 \mathrm{~m}$ de altitud. El Santuario ocupa la parte alta y media de la hoya hidrográfica de la quebrada El Asiento, que se origina en la cima del cerro Tabaco, a la que se les unen las quebradas Los Bollenes y Las Chilcas en el curso intermedio. La quebrada principal en su primera sección tiene un escurrimiento norte-sur, para luego, alrededor de los $1.300 \mathrm{~m}$ s.n.m., cambiar su orientación a noroeste-sureste. La quebrada El Asiento es tributaria del estero Seco, antes de su confluencia con el río Aconcagua. En el Santuario existen dos grandes formaciones geológicas, en primer lugar, la formación Las Chilcas, la cual se distribuye en las zonas bajas y cordón montañoso poniente, y en segundo lugar, en el cerro Tabaco y flanco oeste de la cuenca de la quebrada El Asiento, donde aflora un cuerpo intrusivo (Batolito andino), el cual intruye a la formación Las Chilcas. Esta diferencia geológica implica que la cuenca es muy dinámica (Corporación CIEM Aconcagua, 2008). De acuerdo al Estudio Agrológico de la V Región (CIREN 1997), el Santuario está ubicado en una serie similar a la Asociación de suelo Challay que forma parte de la familia de los Mollisol, con características de franca, fina, mixta y térmica. La profundidad efectiva varía entre los 20 y $70 \mathrm{~cm}$, temiendo una relación directa con la pendiente, la que varía entre $10 \%$ y más de $50 \%$, también el grado de pedregosidad, que va entre escaso a muy abundante, al igual que los afloramientos rocosos.

Entre los trabajos sobre floras regionales disponibles se cuenta con un catálogo a nivel regional (Novoa \& Matus 2013), en el que se da cuenta de 1726 especies, de las que $1357(78,6 \%)$ son nativas, con $689(50,8 \%)$ endémicas de Chile y $369(21,4 \%)$ alóctona asilvestradas. Además, se encuentran publicaciones que han aportado al conocimiento de la flora vascular de la ecorregión mediterránea central y en particular para la Región de Valparaíso. Respecto de la flora de la precordillera se dispone de trabajos sobre Los Andes (Quintanilla 1978) y de Los Patos (Luebert \& Gajardo 2004). En relación con la Cordillera de la Costa, se cuenta con antecedentes de la flora y vegetación del Parque
Nacional La Campana (Luebert et al. 2002), del Santuario de la Naturaleza Palmar El Salto (Flores \& Aguirre 2008), de la cordillera de El Melón y del cerro Tabaco (Flores \& Amigo 2013).

La quebrada El Asiento y el cerro Tabaco fueron conocidos en el ámbito científico luego de su descubrimiento "casual" en 1955, según indica el propio autor (Schlegel 1962), de la población más septentrional de Austrocedrus chilensis (D. Don) Pic.Serm. \& Bizzarri en los faldeos sur del cerro Tabaco. Luego de ese trabajo pionero, se han llevado a cabo otros estudios relacionados con especies amenazadas (Gajardo et al. 1987; Hechenleitner et al. 2005), con el estado de conservación del rodal (Madrid 2005), con la flora y vegetación de la serranía El Asiento (Del Campo 2005; Galarce \& Trivelli 2013) y con la planificación y gestión del área (Corporación Ciem Aconcagua 2004, 2006, 2008, 2014, Madrid 2006). La milenaria población de A. chilensis de El Asiento ha sido motivo de estudios específicos, principalmente vinculados a la dendrocronología y a su relación con el clima, entre los que destacan los de $\mathrm{La}$ Marche et al. (1979) y Le Quesne et al. (2006, 2009). De interés es lo señalado en Le Quesne et al. (2014), en relación con el hallazgo en la localidad del ejemplar vivo de A. chilensis más longevo que hasta ahora se conoce con al menos 1430 años. Luego del incendio ocurrido en marzo de 2016, se está desarrollando un proyecto de restauración ecológica (Corporación Ciem Aconcagua 2017).

En términos de la conservación ambiental las serranías del cerro Tabaco fueron propuestas como sitio de prioridad III “de interés" por Muñoz et al. (1996), ello por constituir el límite septentrional de Austrocedrus chilensis. Actualmente, este sector es parte del sitio "Cerro Tabaco" priorizado como "importante" en la Estrategia y Plan de Acción para la Conservación de la Diversidad Biológica de la Región de Valparaíso (CONAMA-PNUD 2005). A partir del 30 de mayo de 2006 las serranías del cerro tabaco se declararon como Santuario de la Naturaleza mediante D.E. N 698 del MINEDUC.

Entre las amenazas destacan los incendios forestales, los cuales sumados a la presencia de ganado vacuno, modifican las características de la comunidad vegetal, ya sea mediante cambios en las condiciones microambientales, en la cobertura, en el número de especies, y/o en las especies que caracterizan el ambiente (Blackhall et al. 2015); ejemplo de esta amenaza ocurrió en marzo de 2016, donde el área protegida se vio afectada por un gran incendio, el cual consumió 745 ha., de las cuales 721 eran parte del Santuario (CONAF 2016). La ganadería se registra en el Santuario mediante un intenso ramoneo de arbustos en el matorral subandino, como también por la mayor cubierta vegetal de alóctonas asilvestradas en las zonas bajas con presencia de ganado, a diferencia de donde queda excluido, lo que también fue reportado por Holmgren et al. (2000). La minería y sus caminos asociados también son una 
amenaza, ya que dentro del Santuario existen minas como Socavón y San Luis, al menos tres pertenencias mineras, $\mathrm{y}$ en las inmediaciones, cuatro faenas mineras activas y doce irregulares (SERNAGEOMIN 2012), sumado a 3,5 $\mathrm{km}$ de caminos vehiculares. Finalmente, la expansión urbana y de la fruticultura en el valle de Aconcagua es un proceso a considerar, ya que ha traspasado los límites del suelo agrícola de valle, abarcando terrenos con pendientes más allá del umbral morfodinámico aconsejable para la explotación agrícola sustentable (Castro et al. 2010). El Santuario no escapa a esta realidad y ya existen viviendas a menos de $1 \mathrm{~km}$ lineal de sus límites y los cultivos agrícolas ya llegan a menos de $2 \mathrm{~km}$.

El objetivo de este trabajo es contribuir al conocimiento de la flora vascular del Santuario de la Naturaleza Serranía El Ciprés, dando a conocer la riqueza y la composición de especies, señalando las especies endémicas locales, regionales o nacionales, las especies incluidas en alguna categoría de conservación y el grado de participación de las alóctonas asilvestradas.

\section{MATERIALES Y MÉTODOS}

\section{CARACTERÍSTICAS del ÁREA DE ESTUdio}

UBICACIÓN

El Santuario de la Naturaleza "Serranía El Ciprés" se localiza en la comuna de San Felipe de Aconcagua, provincia homónima, Región de Valparaíso, aguas arriba y al oeste de la localidad de El Asiento, a unos $11 \mathrm{~km}$ al noroeste de la plaza de armas de la ciudad de San Felipe. El Santuario se ubica en el cordón montañoso transversal de Putaendo, que conecta la Cordillera de la Costa (macizo El Melón), con la Cordillera de los Andes (altos de Alicahue), en la cuenca baja del río Putaendo. El área de este estudio está comprendida entre las coordenadas $32^{\circ} 38^{\prime} 40^{\prime \prime}-32^{\circ} 41^{\prime} 30^{\prime \prime} \mathrm{S}$ y $70^{\circ} 46^{\prime} 40^{\prime \prime}-70^{\circ} 50$ ' $10^{\prime \prime} \mathrm{W}$ (Figs 1 y 2 ).

El área incluye un solo predio, el que pertenece a la comunidad agrícola El Asiento; comprende unas 1700 ha, de las que 1114,8 ha fueron declaradas como Santuario de la Naturaleza el 30 de mayo de 2006.

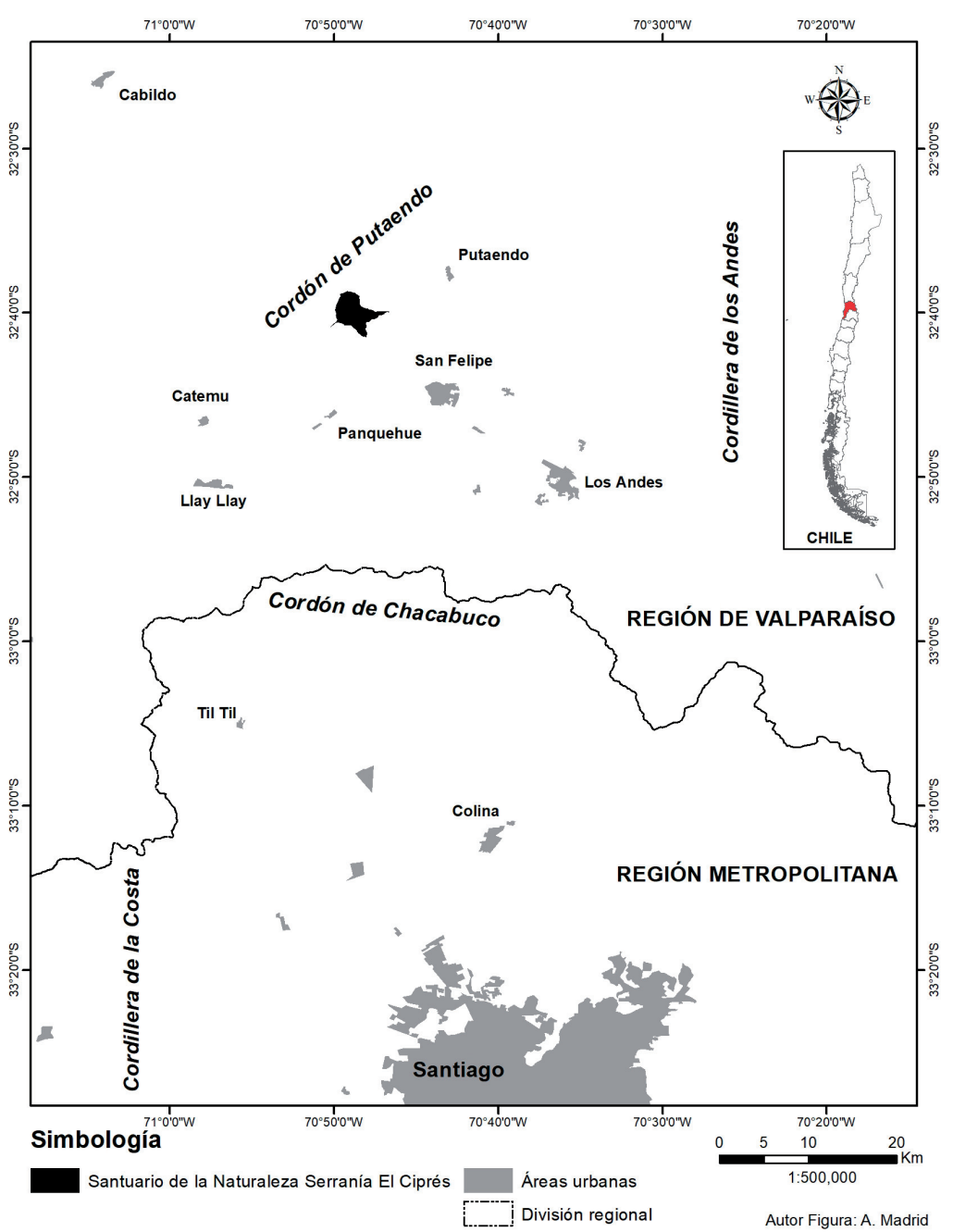

FIGURA 1. Ubicación geográfica del área de estudio a nivel regional. / Geographic location of the study area on a regional level. 
Gayana Bot. 75(2), 2018

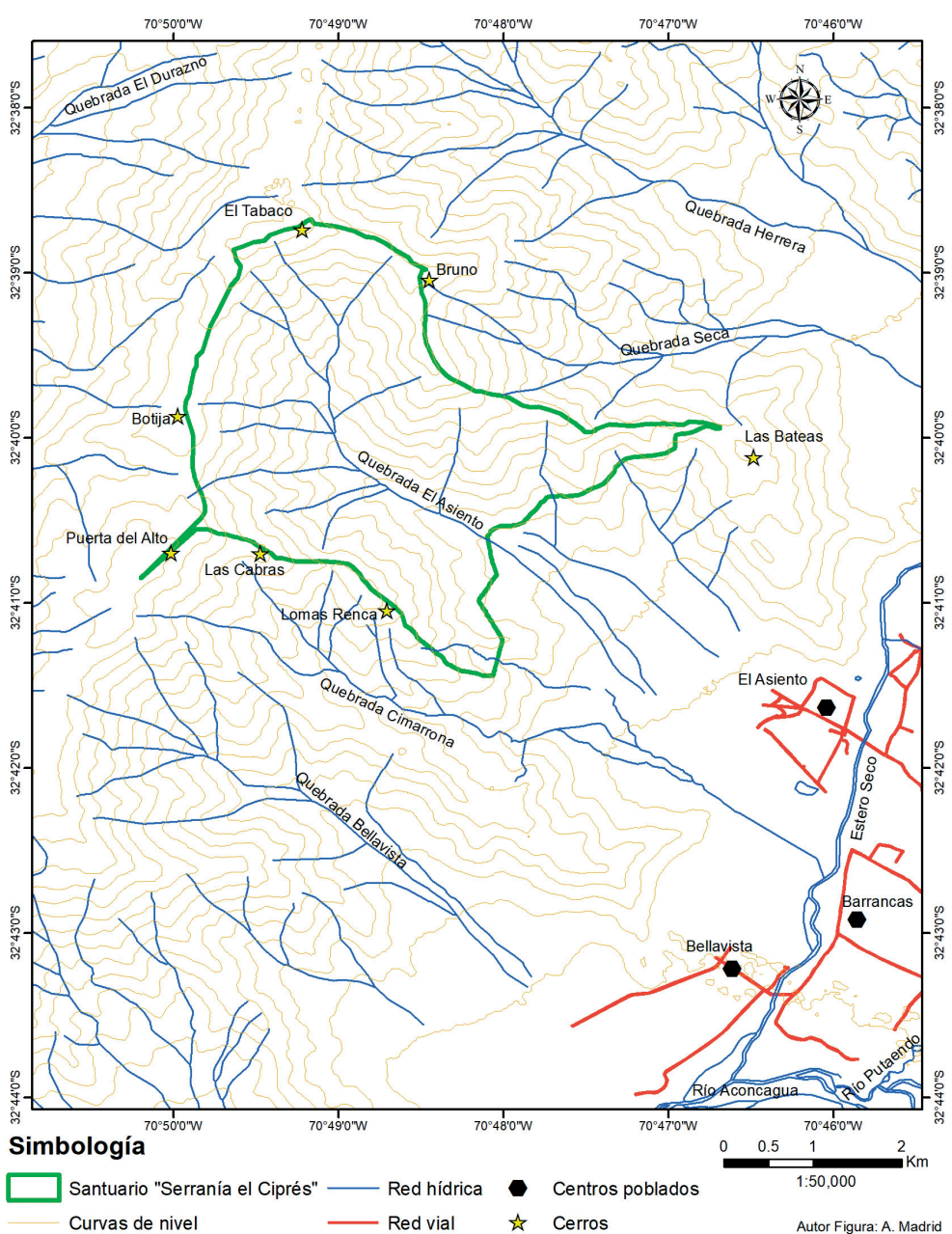

Figura 2. Esquema del área de estudio a nivel local. / Diagram of the study area at local level.

El clima de la Región de Valparaíso según Luebert \& Pliscoff (2012) considera cinco tipos de bioclima, dos de ellos en el Santuario. Primero, el bioclima del "interior" se registra en los sectores más secos, sometidos a efectos de sombra de lluvia, en los sectores con menor altitud (0-1300 m) y en los sitios planos del interior. La temperatura media anual alcanza en promedio a $14,9^{\circ} \mathrm{C}$; la amplitud térmica anual, a $8,6^{\circ} \mathrm{C}$ y las precipitaciones, a unos $304 \mathrm{~mm} / \mathrm{año}$, las más reducidas de la Región de Valparaíso.

Segundo, el bioclima de las "serranías interiores" se manifiesta en las áreas montañosas, tanto en la Cordillera de la Costa como en la de los Andes, entre 600 y 2000 m de altitud. La temperatura media anual promedio registra $12,1{ }^{\circ} \mathrm{C}$; la amplitud térmica anual, un promedio de $8,9^{\circ} \mathrm{C}$ y las precipitaciones, $377 \mathrm{~mm} / a$ ño. En el Santuario sobre los $1800 \mathrm{~m}$ se registran precipitaciones bajo la forma de lluvia o nieve, ésta última se acumula y permanece largos períodos en las laderas de umbría.

En cuanto a la vegetación regional, Quintanilla (1978) da cuenta de tres pisos de vegetación en estas latitudes de los Andes: montañoso (800 a $1400 \mathrm{~m})$, subandino (1400 a $2.000 \mathrm{~m}$ ) y andino (2.000 a 2.800-3.000 m). Luego Gajardo (1994) propone, para la parte inferior del área de estudio, las formaciones del matorral espinoso de las serranías y del matorral esclerófilo andino para la superior. Luebert \& Pliscoff (2006), a su vez, señalan que la vegetación se incluye en los pisos de vegetación del matorral espinoso mediterráneo interior de Trevoa quinquinervia Gillies \& Hook. y Colliguaja odorifera Molina en el sector basal y el del matorral arborescente esclerófilo de Quillaja saponaria Molina y Porlieria chilensis I.M. Johnst., en el sector más alto. Finalmente, Flores \& Amigo (2013) presentan una propuesta detallada de unidades de vegetación para los cerros El Melón y Tabaco.

A partir de dichas propuestas y con el fin de obtener unidades homogéneas de vegetación a escala del Santuario, la vegetación se clasificó en cinco unidades definidas por sus especies dominantes y su fisonomía, cuya distribución local obedece al gradiente de altitud y a las diferencias de exposición de las laderas, las que se describen a continuación. 
Matorral xerófilo, vegetación con cobertura media, dominada por Puya alpestris (Poepp.) Gay subsp. zoellneri, Colliguaja odorifera y Lithrea caustica (Molina) Hook. \& Arn. acompañadas por Krameria cistoidea Hook. \& Arn., Trichocereus chiloensis (Colla) Britton \& Rose y Muehlenbeckia hastulata (Sm.) I.M. Johnst.; en el estrato de hierbas son abundantes Plantago hispidula Ruiz \& Pav., Clarkia tenella (Cav.) H.F. Lewis \& M.R. Lewis y Chaetanthera moenchioides Less. Se localiza entre los 1.000 y $1.600 \mathrm{~m}$ de altitud en laderas de exposición ecuatorial. En su límite superior aparece Festuca acanthophylla E. Desv. para hacer una transición hacia el matorral subandino, por su parte en la zona inferior comienzan a aparecer elementos aislados del bosque esclerófilo con el que es contiguo.

Matorral esclerófilo arborescente, formación arborescente, abierta, dominada por arbustos altos como Gochnatia foliolosa (D. Don) D. Don ex Hook. \& Arn. y Kageneckia oblonga Ruiz \& Pav., con crecimiento de arbusto; en el estrato de los árboles, bastante discontinuo, destacan Lithraea caustica y Quillaja saponaria; en el de las hierbas, aparecen con frecuencia Poa gayana E. Desv., Oxalis rosea Jacq. y Geranium berteroanum Colla. Se distribuye en las laderas de exposición polar y en quebradas intermedias entre los 1.000 y $1.600 \mathrm{~m}$ de altitud. En su límite superior Festuca acanthophylla comienza a incrementar su abundancia en una zona de transición hacia el matorral subandino, mientras que en su parte inferior Colletia hystrix Clos articula con el bosque esclerófilo.

Bosque esclerófilo, bosque poco denso dominado por árboles como Quillaja saponaria y Lithraea caustica, acompañados por Acacia caven (Molina) Molina, Colliguaja odorifera y Kageneckia oblonga; en sitios más húmedos aparecen Cryptocarya alba (Molina) Looser, Maytenus boaria Molina y Aristotelia chilensis (Molina) Stuntz. Es la segunda unidad de vegetación con menor superficie en el Santuario y se restringe a los fondos de las principales quebradas hasta los $1.600 \mathrm{~m}$ de altitud, donde da paso al matorral subandino, mientras que en zonas más bajas se articula con el matorral xerófilo y con el matorral esclerófilo arborescente.

Matorral subandino, vegetación abierta y heterogénea. En gran parte de la superficie está dominada por Festuca acanthophylla, Azorella prolifera (Cav.) G.M. Plunkett \& A.N. Nicolas, Chuquiraga oppositifolia D. Don, Calceolaria segethii Phil., Colliguaja salicifolia Gillies \& Hook. y Tetraglochin alatum (Gillies ex Hook. \& Arn.) Kuntze; en su parte inferior, aparecen ejemplares aislados de Quillaja saponaria, y más arriba de Kageneckia angustifolia D. Don. En esta unidad destaca Austrocedrus chilensis, cuyos ejemplares se encuentran distribuidos en una única población en las laderas de exposición sur; en las hierbas abundan Quinchamalium chilense Molina, Chaetanthera linearis Poepp. y Valeriana stricta Clos. Se distribuye de forma continua en las laderas entre los $1.500-1.600$ y 2.200 $\mathrm{m}$ de altitud. Es la unidad de vegetación que ocupa la mayor superficie en el Santuario.

Matorral andino, vegetación con escasa cobertura, que alterna con herbazales de altura; está restringida a los sectores planos o semiplanos, sobre los 2.100-2.200 m de altitud. Entre los arbustos predominan Fabiana imbricata Ruiz \& Pav., Anarthrophyllum cumingii (Hook. \& Arn.) F. Phil., Junellia spathulata (Gillies \& Hook.) Moldenke, Tetraglochin alatum y Chuquiraga oppositifolia; son abundantes Nardophyllum lanatum (Meyen) Cabrera, Viviania marifolia Cav. y Acaena pinnatifida Ruiz \& Pav. Destaca Eriosyce aurata (Pfeiff.) Backeb. en la planicie de la cumbre. Es la unidad con menor superficie del Santuario, representando solo la parte inferior de este piso de vegetación.

\section{MÉTODOS FLORÍSTICOS}

La metodología utilizada para determinar la riqueza de especies durante los trabajos de terreno consideró un muestreo estratificado dirigido hacia las cinco unidades de vegetación consideradas para este trabajo, mediante la realización de transectos libres de $10 \mathrm{~m}$ de ancho. En total se realizaron catorce (14) transectos, totalizando 44.674 metros lineales muestreados, equivalentes a $0,044 \mathrm{~km}^{2}$. Los transectos tuvieron longitudes variables desde los $328 \mathrm{~m}$ (transecto $\mathrm{N}^{\circ} 10$ ) a los $9.384 \mathrm{~m}$ (transecto $\mathrm{N}^{\circ} 11$ ), con una media de $3.191 \mathrm{~m}$ (Fig. 3).

El registro en terreno se llevó a cabo en nueve campañas, cinco durante 2013 (dos en agosto, dos en octubre y una en diciembre), una en 2014 (marzo) y tres en 2015 (enero, octubre y diciembre), con el fin de abordar todas las estaciones del año. Las campañas consideraron entre uno y tres días de terreno y siempre a los dos primeros autores.

En los transectos realizados se fueron registrando todas las especies presentes, georreferenciando el primer punto de registro de la especie mediante GPS (coordenadas LS, LW y altitud), señalando la unidad de vegetación correspondiente, su abundancia relativa (DAFOR) y recolectando material vegetal para ser herborizado y determinado en gabinete utilizando la bibliografía taxonómica pertinente. El material recolectado en este trabajo quedó depositado en el herbario de la Universidad de Concepción (CONC) y algunas copias en el del Museo Nacional de Historia Natural de Santiago (SGO).

Se obtuvo una lista de las especies, donde la nomenclatura sigue en general a Zuloaga et al. (2008) y a Marticorena y Rodríguez (1995, 2001, 2003, 2005, 2011). Tanto la secuencia sistemática de la lista como la nomenclatura y la circunscripción de los órdenes y las familias de angiospermas se basan en la propuesta del grupo APG IV (2016). Se ha adoptado esta perspectiva filogenética por reflejar de manera más adecuada la posición evolutiva de cada orden y familia en el sistema de clasificación taxonómico (Judd et al. 2008). Por su parte, a cada especie se le asignó una forma 
de vida de Raunkiaer (Braun-Blanquet 1979).

El origen geográfico de las especies, endémica de Chile, nativa o alóctona asilvestrada, se asigna según Matthei (1995), Zuloaga et al. (2008a) y Fuentes et al. (2013). Se reportan, aquellas especies cuyo registro constituye un límite nuevo en su distribución o que tienen distribuciones restringidas a nivel nacional.
Para cada especie se da a conocer el rango de altitud y la unidad de vegetación donde fue registrada. Además se citan los materiales de herbario que respaldan su mención, salvo en los casos en que su presencia se basa en un registro visual. Finalmente se da cuenta del estado de conservación de las especies mediante la revisión de las clasificaciones oficiales disponibles al año 2017 (MINSEGPRES-CONAMA y MMA).

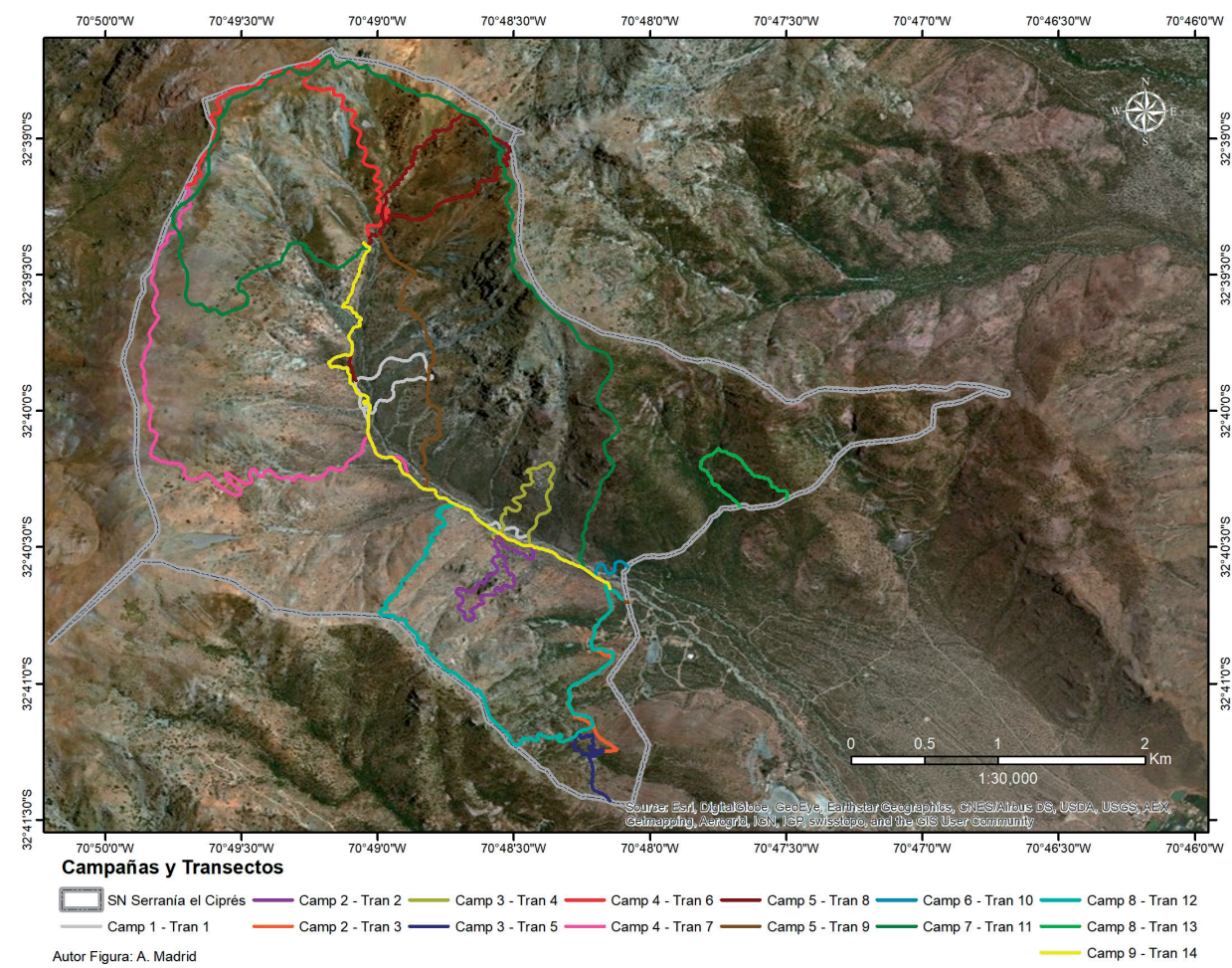

Figura 3. Transectos realizados para registrar la flora del Santuario de la Naturaleza Serranía El Ciprés. / Transects carried out to register the flora of the Serranía El Ciprés Nature Sanctuary.

La abundancia relativa de las especies se caracterizó al nivel del Santuario, mediante una adaptación de la escala DAFOR, donde fueron "dominantes" aquellas que predominan en su unidad de vegetación, fueron observadas en nueve o más transectos y/o en más de la mitad de la superficie de la unidad de vegetación prospectada por los transectos, para el caso del matorral andino; "abundantes", las que acompañan a las dominantes, están presentes en gran número, pero menor que las dominantes, distribuidas en toda la unidad, pero observadas en seis a ocho transectos; "frecuentes", las que se aparecen en forma continua, pero con número de ejemplares que no alcanza para considerarlas abundantes, observadas en tres a cinco transectos; "ocasionales", aquellas escasas que se distribuyen de forma discontinua, observadas en dos transectos, y "raras", aquellas con muy pocos individuos, distribuidas de forma aislada, y que solo fueron observadas en un trasecto, algunas en tramos puntuales (http://www.botanicalkeys. co.uk/northumbria/dafor.asp).

\section{RESULTADOS}

RiQUEZA Y COMPOSICIÓN DE LA FLORA VASCULAR La riqueza del Santuario alcanzó a 293 especies (297 taxa). La lista detallada de ellas indicando la familia, el nombre científico, la forma de vida de Raunkiaer, el origen geográfico, el rango de altitud, la unidad de vegetación y la categoría de conservación se muestra en el Anexo 1. Las 293 especies se incluyen en 183 géneros y 74 familias. Las familias con mayor número de especies son Asteraceae con $48(16,4 \%)$, Fabaceae s.l. con $17(5,8 \%)$ y Poaceae con $16(5,5 \%)$, con entre diez y seis especies aparecen Apiaceae, Calceolariaceae, Amaryllidaceae, Boraginaceae, Pteridaceae, Solanaceae, Caprifoliaceae (incluye Valeriana), Rosaceae y Montiaceae. Los géneros con mayor riqueza son: Calceolaria con diez especies, Adesmia con ocho, Mutisia y Valeriana con seis, Oxalis con cinco, y Chaetanthera, Dioscorea, Escallonia, Leucheria, Schinus y Senecio con cuatro. 
DisTRIBUCIÓN GEOGRÁFICA

En relación con este aspecto, 272 especies son nativas o autóctonas $(92,8 \%)$, de las que $145(53,3 \%)$ son endémicas de Chile. Se encontraron, además, 21 especies alóctonas asilvestradas $(7,2 \%)$. Las especies nativas propias de la ecorregión mediterránea de Chile (sur de la Región de Atacama a la de Bíobío) alcanzan a 119 , un $43,8 \%$ de las nativas, por su parte, las especies restringidas entre las regiones de Coquimbo y O'Higgins a 37, un 13,6\% de las especies nativas.

\section{FORMAS DE VIDA}

El análisis de las formas de vida de las plantas muestra que la flora registrada en el Santuario está formada por 77 especies de hemicriptófitas $(26,4 \%)$, en general, herbáceas perennes; 69 especies de terófitas $(23,5 \%)$, considera hierbas anuales; 52 especies de caméfitas $(17,7 \%)$, principalmente arbustos bajos; 43 especies de nanofanerófitas (14,7\%), arbustos; 29 especies de criptófitas del tipo geófitas $(9,9 \%)$; y 23 especies de fanerófitas (7,8\%), árboles (Tabla 1).

En la flora autóctona, incluyendo las nativas y las endémicas de Chile, predominan las hemicriptófitas con un $27,6 \%$, las terófitas alcanzan a un $19,1 \%$ y las geófitas un $10,6 \%$. Entre las especies leñosas predominan las caméfitas con un $19,1 \%$, un $15,1 \%$ son nanofanerófitas y las fanerófitas llegan a un 8,5\%. Entre las alóctonas asilvestradas o introducidas predominan las terófitas, principalmente hierbas anuales con un $81 \%$, las que crecen frecuentemente en los ambientes más perturbados. En todos los tipos de formas de vida predominan las especies nativas.

\section{FLORA POR TIPO DE VEGETACIÓN}

Las unidades de vegetación con mayor riqueza de especies corresponden al matorral subandino (125 especies), matorral esclerófilo arborescente (124 especies) y al matorral xerófilo (119 especies). Respecto de la distribución de las formas de vida por unidad de vegetación destaca la riqueza de especies de las hemicriptófitas y las terófitas en casi todas las formaciones (Tabla 2), las caméfitas son importantes en los matorrales subandino y andino y las fanerófitas en el bosque esclerófilo.

En relación con el grado de endemismo, destaca el matorral esclerófilo arborescente con un $58,4 \%$, en el otro extremo se encuentra el matorral andino con $35 \%$, producto que a mayor altitud las formaciones incluyen más especies compartidas con Argentina. En cuanto a las alóctonas asilvestradas, ellas alcanzan su mayor riqueza en el matorral xerófilo (16 especies), seguido del matorral esclerófilo arborescente (11), para casi desaparecer en el matorral andino con solo una especie (Tabla 3).

TABLA 1. Forma de vida según Raunkiaer (1934). Na: nativas; AA: alóctonas asilvestradas. / Life form according to Raunkiaer (1934). Na: native; AA: alien plants.

\begin{tabular}{|c|c|c|c|c|c|c|}
\hline FORMA DE VIDA & TOTAL & $\%$ & $\mathrm{Na}$ & $\%$ & AA & $\%$ \\
\hline Caméfita & 52 & 17,7 & 52 & 19,1 & 0 & 0 \\
\hline Fanerófita & 23 & 7,8 & 23 & 8,5 & 0 & 0 \\
\hline Geófita & 29 & 9,9 & 29 & 10,6 & 0 & 0 \\
\hline Hemicriptófita & 77 & 26,3 & 75 & 27,6 & 2 & 4,5 \\
\hline Nanofanerófita & 43 & 14,7 & 41 & 15,1 & 2 & 4,5 \\
\hline Terófita & 69 & 23,5 & 52 & 19,1 & 17 & 81 \\
\hline Total & 293 & & 272 & & 21 & \\
\hline
\end{tabular}

TABLA 2. Riqueza de especies por forma de vida y unidad de vegetación. / Species richness by life form and vegetation type.

\begin{tabular}{|c|c|c|c|c|c|}
\hline $\begin{array}{l}\text { FORMA DE VIDA / } \\
\text { UNIDAD DE VEGETACIÓN }\end{array}$ & $\begin{array}{c}\text { BOSQUE } \\
\text { ESCLERÓFILO }\end{array}$ & $\begin{array}{l}\text { MATORRAL } \\
\text { XERÓFILO }\end{array}$ & $\begin{array}{c}\text { MATORRAL ESCLERÓFILO } \\
\text { ARBORESCENTE }\end{array}$ & $\begin{array}{l}\text { MATORRAL } \\
\text { SUBANDINO }\end{array}$ & $\begin{array}{l}\text { MATORRAL } \\
\text { ANDINO }\end{array}$ \\
\hline Caméfita & 9 & 13 & 13 & 37 & 14 \\
\hline Fanerófita & 17 & 7 & 14 & 7 & 0 \\
\hline Geófita & 9 & 10 & 14 & 8 & 5 \\
\hline Hemicriptófita & 18 & 25 & 36 & 38 & 15 \\
\hline Nanofanerófita & 16 & 16 & 17 & 16 & 4 \\
\hline Terófita & 24 & 48 & 30 & 19 & 3 \\
\hline Riqueza Total & 93 & 119 & 124 & 125 & 41 \\
\hline
\end{tabular}


Gayana Bot. 75(2), 2018

TABLA 3. Origen geográfico por unidad de vegetación. / Geographical origin by vegetation type.

\begin{tabular}{|c|c|c|c|c|c|}
\hline & $\begin{array}{c}\text { BosQue } \\
\text { ESCLERÓFILO }\end{array}$ & $\begin{array}{l}\text { MATORRAL } \\
\text { XERÓFILO }\end{array}$ & $\begin{array}{c}\text { MATORRAL ESCLERÓFILO } \\
\text { ARBORESCENTE }\end{array}$ & $\begin{array}{l}\text { MATORRAL } \\
\text { SUBANDINO }\end{array}$ & $\begin{array}{c}\text { MATORRAL } \\
\text { ANDINO }\end{array}$ \\
\hline Endémica de Chile & 45 & 52 & 66 & 54 & 14 \\
\hline Nativa no endémica & 39 & 51 & 47 & 65 & 26 \\
\hline Alóctona asilvestrada & 9 & 16 & 11 & 6 & 1 \\
\hline Total & 93 & 119 & 124 & 125 & 41 \\
\hline Grado de endemismo & $53,6 \%$ & $50,5 \%$ & $58,4 \%$ & $45,4 \%$ & $35,0 \%$ \\
\hline
\end{tabular}

TABLA 4. Especies con frecuencia "rara" en el Santuario por unidad de vegetación. / Frequency "rare" species in the Sanctuary by vegetation type.

\begin{tabular}{ll}
\hline ESPECIES RARAS & UNIDADES DE VEGETACIÓN \\
\hline Prosopis chilensis & Bosque esclerófilo \\
Schinus areira & Matorral xerófilo \\
Citronella mucronata & Matorral esclerófilo arborescente, en su límite superior \\
Junellia cinerascens & Matorral esclerófilo arborescente \\
Pellaea myrtillifolia & Matorral esclerófilo arborescente \\
Pleurosorus papaverifolius & Matorral esclerófilo arborescente \\
Schinus kauselii & Matorral esclerófilo arborescente \\
Blechnum hastatum & Matorral subandino, fondos de quebrada \\
Cortaderia rudiuscula & Matorral subandino, fondos de quebrada \\
Ourisia serpyllifolia & Matorral subandino, fondos de quebrada \\
Rubus ulmifolius & Matorral subandino, fondos de quebrada \\
Adesmia rubroviridis & Matorral subandino, en su límite superior \\
Alstroemeria parvula & Matorral andino \\
Blechnum microphyllum & Matorral andino \\
Blumenbachia dissecta & Matorral andino \\
Cryptantha capituliflora & Matorral andino \\
Puya coerulea & Matorral andino \\
\hline
\end{tabular}

En cuanto a la estimación general de la abundancia relativa de las especies utilizando la escala DAFOR, se registraron $15(5,1 \%)$ de especies dominantes, corresponden a Puya alpestris subsp. zoellneri, Colliguaja odorifera, Lithraea caustica, Quillaja saponaria, Gochnatia foliolosa, Kageneckia oblonga, Festuca acanthophylla, Tetraglochin alatum, Calceolaria segethii, Colliguaja salicifolia, Kageneckia angustifolia, Chuquiraga oppositifolia, Azorella prolifera, Fabiana imbricata y Anarthrophyllum cumingii. Por otra parte, $39(13,4 \%)$ especies fueron abundantes, 138 (47,3\%) especies frecuentes, 83 (28,4\%) especies ocasionales y 17 (5,8\%) especies raras (Tabla 4).
ESPECIES EN CATEGORÍA DE CONSERVACIÓN

En el área de estudio se registraron cinco especies clasificadas como "vulnerables": Citronella mucronata (Ruiz \& Pav.) D. Don (DS 16/2016 MMA), Eriosyce aurata (DS 43/2013 MMA), Placea ornata Miers ex Lindl. (DS 19/2012 MMA), Porlieria chilensis (DS 51/2008 MINSEGPRES) y Prosopis chilensis (Molina) Stuntz emend. Burkart (DS 13/2013 MMA) sumado a cinco "casi amenazadas": Austrocedrus chilensis (DS 42/2011 MMA), Kageneckia angustifolia (DS 19/2012 MMA), Pellaea myrtillifolia Mett. ex Kuhn (DS 13/2013 MMA), Solaria miersioides Phil. (DS 19/2012 MMA) y Trichocereus chiloensis (DS 41/2011 MMA) de acuerdo al Reglamento de Conservación de Especies (RCE). 


\section{DISCUSIÓN Y CONCLUSIONES}

RiQuEZA Y COMPOSICIÓN

En base a estos resultados, la flora vascular del Santuario de la Naturaleza Serranía El Ciprés, formada por 293 especies, comprende al menos un 5,7\% de la flora de Chile continental (5105 especies, Marticorena 1990). En relación con la flora nativa del área de clima mediterráneo de Chile, la que contiene unas 2593 especies (Arroyo \& Cavieres 1997), las especies del Santuario representan un 11,3\% del total. Respecto de la riqueza taxonómica de la flora de Chile continental (Marticorena 1990), en el Santuario se registraron especies de un $18,2 \%$ de los 1008 géneros y un $40,2 \%$ de las 184 familias.

Respecto de la flora nativa de la Región de Valparaíso, (1357 especies, Novoa \& Matus 2013), la riqueza del Santuario representa un $20 \%$. En términos de riqueza taxonómica, se encuentran representados un 37,8\% de los géneros y un 50,3\% de las familias de la Región.

Estos valores muestran la importancia de esta área protegida a nivel regional, la cual en una superficie de 11,1 $\mathrm{km}^{2}$, equivalente al 0,7\% de la Región de Valparaíso, alberga una elevada muestra de su diversidad vegetal, especialmente en una región donde las siete áreas protegidas del Estado representan el 2,71\% de su superficie (INE 2017), los trece santuarios regionales incrementan dicha protección en apenas un $0,15 \%$ (MMA 2018) y las iniciativas de conservación privada suman un 1,3\% (MMA-GEF 2016), estando protegida en menos del $5 \%$ de su superficie total. De forma adicional, de los dos pisos de vegetación de Luebert \& Pliscoff (2006) presentes en el Santuario, el bosque espinoso mediterráneo interior de Acacia caven y Prosopis chilensis no se encuentra protegido y el matorral arborescente esclerófilo mediterráneo interior de Quillaja saponaria y Porlieria chilensis se encuentra protegido solo en un $1,4 \%$ de su superficie, por lo que el aporte del Santuario en su protección es relevante, tomando en cuenta su elevada riqueza de especies nativas. En cuanto a los pterófitos, destaca la presencia de 12 especies, similar a lo observado por Parra y Pichuantes (1981) para el valle de Putaendo (13), sumando ahora Blechnum microphyllum (Goldm.) C.V. Morton y Cryptogramma fumariifolia (Phil. ex Baker) H. Christ.

En relación con los datos sobre la flora de las serranías del cerro Tabaco obtenidos mediante la revisión bibliográfica (Flores \& Amigo 2013, Galarce \& Trivelli 2013, Arón Cádiz com.pers.), se encontraron 32 especies que se distribuyen en estas serranías, pero no necesariamente en el marco de los límites del Santuario, lo que eleva la riqueza de estas serranías hasta unas 325 especies (Tabla 4).

Sobre la riqueza del Santuario es importante señalar que el número de especies nativas, 272, es mayor que el valor esperado para la misma superficie, de acuerdo con una fórmula propuesta para predecir la riqueza en función de la superficie, para la flora de Chile central, la que para los 11,1 $\mathrm{km}^{2}$ predice 226 especies (Arroyo et al. 2002).

Esta alta riqueza y proporción de especies nativas puede explicarse, en parte, por la heterogeneidad ambiental y el buen estado de conservación que tenía la vegetación, al menos hasta el gran incendio de 2016, sumado al compromiso de conservarlo y decisiones como la supresión de ganado caprino hace más de quince años, pero también por constituirse en una zona de transición entre ambientes de condiciones semidesérticas que se distribuyen hacia el norte con ambientes propios de la zona centro sur de Chile, además de constituir una zona de transición entre ambientes continentales y de influencia oceánica dada por su condición de corredor montañoso transversal.

Al analizar la distribución geográfica de las especies es relevante informar la persistencia de la población de Austrocedrus chilensis en su límite norte de su distribución (Schlegel 1962), la principal justificación del otorgamiento de la calidad de Santuario.

Se reportan otras siete especies que amplían sus límites de distribución en este trabajo y constituyen un hallazgo regional, las que corresponden como nuevo límite norte a Blechnum microphyllum, citada entre las regiones Metropolitana y Los Lagos, Polypogon cf. imberbis (Phil.) Johow, citada entre las regiones del Maule y Los Lagos, Rhodolirium montanum Phil., citada entre las regiones Metropolitana y Maule, Solaria miersioides, citada para las regiones Metropolitana, Maule y Biobío y, Viola subandina J.M. Watson, citada entre las regiones Metropolitana y Biobío. Como nuevo límite sur, se da cuenta de Herniaria cinerea DC., alóctona asilvestrada, nuevo límite a nivel nacional; citada solo para la Región de Coquimbo y Junellia cinerascens (Schauer) Botta, también citada solo para Coquimbo (Peralta et al. 2008).

Por otra parte, son cuatro especies las que amplían una porción de su distribución, a saber, Adesmia rubroviridis Burkart, la cual alcanza en el Santuario su límite sureste, ya que se la había considerado endémica de la Región de Coquimbo (Marticorena et al. 2001), pero fue citada posteriormente para la Quebrada Garretón y en la Cordillera El Melón (JBN 2008; Flores \& Amigo 2013). Por su parte, Alstroemeria parvula Phil. es la primera población registrada fuera de la Cordillera de los Andes, ampliando su límite hacia el oeste por los cordones transversales, citada para las regiones de Valparaíso y Metropolitana. Un caso algo particular es Citronella mucronata, ya que si bien crece más al norte por la costa (Región de Coquimbo), aquí encuentra su límite nororiente en los cordones transversales andinos, ya que en estas latitudes solo había sido citada para la cordillera de El Melón, en la cordillera de la Costa (mapa distribución especie, ficha RCE $12^{\circ}$ Proceso). Adicionalmente, Placea ornata encontraría aquí su límite centro norte de distribución, tratándose de una especie restringida a las regiones Valparaíso y Metropolitana. El caso de Sisyrinchium nigricans Gay es particular, ya que 
Rodríguez (1986) la considera sinónima de Sisyrinchium striatum Sm., pero nos parece una especie buena, cuyo tipo es de la cordillera de Ovalle (Región de Coquimbo). De forma adicional, 27 especies encuentran en la Región de Valparaíso su límite norte de distribución, sumado a Cristaria multiflora Gay que encuentra en esta región su límite sur (Tabla 6), lo que se traduce en que el 13,7\% de las especies se encuentran en sus extremos de distribución.
DisTRIBUCIÓN GEOGRÁFICA

El grado de endemismo alcanza a un 53,3\%, siendo mayor al 46,3\% propuesto para la flora de la ecorregión mediterránea de Chile (Arroyo \& Cavieres 1997) y también, levemente mayor al grado de endemismo general de Chile continental, $51,8 \%$ propuesto por Marticorena (1990).

Las alóctonas asilvestradas llegan a un 7,2\% (21 especies), porcentaje menor que el registrado para la flora

TABLA 5. Flora citada para las serranías del cerro Tabaco que no fue encontrada en este estudio. / Flora cited for the range of the Tabaco hill that was not found in this study.

\begin{tabular}{|c|c|c|}
\hline FAMILIA & ESPECIE & FUENTE \\
\hline Adiantaceae & Adiantum gertrudis & Flores-Toro \& Amigo (2013) \\
\hline Adiantaceae & Adiantum sulphureum & Flores-Toro \& Amigo (2013) \\
\hline Apiaceae & Bowlesia incana & Flores-Toro \& Amigo (2013) \\
\hline Asteraceae & Haplopappus donianus & Flores-Toro \& Amigo (2013) \\
\hline Asteraceae & Haplopappus pinnatifidus & Flores-Toro \& Amigo (2013) \\
\hline Asteraceae & Pachylaena atriplicifolia & Cádiz (com.pers.) \\
\hline Asteraceae & Senecio eruciformis & Flores-Toro \& Amigo (2013) \\
\hline Asteraceae & Senecio microphyllus & Flores-Toro \& Amigo (2013) \\
\hline Blechnaceae & Blechnum chilense & Cádiz (com.pers.) \\
\hline Bromeliaceae & Puya chilensis & Flores-Toro \& Amigo (2013) \\
\hline Calceolariaceae & Calceolaria arachnoidea subsp. nubigena & Flores-Toro \& Amigo (2013) \\
\hline Calceolariaceae & Calceolaria nudicaulis & Cádiz (com.pers.) \\
\hline Calceolariaceae & Calceolaria petiolaris & Galarce \& Trivelli (2013) \\
\hline Fabaceae & Adesmia exilis & Flores-Toro \& Amigo (2013) \\
\hline Fabaceae & Astragalus darumbium & Flores-Toro \& Amigo (2013) \\
\hline Fabaceae & Otholobium glandulosum & Cádiz (com.pers.) \\
\hline Grossulariaceae & Ribes punctatum & Galarce \& Trivelli (2013) \\
\hline Grossulariaceae & Ribes nubigenum & Flores-Toro \& Amigo (2013) \\
\hline Lythraceae & Pleurophora polyandra & Flores-Toro \& Amigo (2013) \\
\hline Malvaceae & Andeimalva chilensis & Flores-Toro \& Amigo (2013) \\
\hline Oxalidaceae & Oxalis compacta & Flores-Toro \& Amigo (2013) \\
\hline Brassicaceae & Descurainia cumingia & Flores-Toro \& Amigo (2013) \\
\hline Poaceae & Nassella chilensis & Flores-Toro \& Amigo (2013) \\
\hline Poaceae & Pappostipa speciosa & Flores-Toro \& Amigo (2013) \\
\hline Pteridaceae & Adiantum gertrudis & Flores-Toro \& Amigo (2013) \\
\hline Pteridaceae & Adiantum sulphureum & Flores-Toro \& Amigo (2013) \\
\hline Rosaceae & Acaena alpina & Cádiz (com.pers.) \\
\hline Sapindaceae & Bridgesia incisifolia & Galarce \& Trivelli (2013) \\
\hline Solanaceae & Lycium chilense & Cádiz (com.pers.) \\
\hline Tropaeolaceae & Tropaeolum ciliatum & Flores-Toro \& Amigo (2013) \\
\hline Tropaeolaceae & Tropaeolum leptophyllum & Flores-Toro \& Amigo (2013) \\
\hline Tropaeolaceae & Tropaeolum looseri & Cádiz (com.pers.) \\
\hline Verbenaceae & Glandularia laciniata & Cádiz (com.pers.) \\
\hline Woodsiaceae & Cystopteris fragilis & Cádiz (com.pers.) \\
\hline
\end{tabular}


de Chile $(11,4 \%)$ y menor también que los de otras áreas protegidas de Chile central como el Monumento Natural El Morado (11,4\%, Teillier et al. 1994), el Santuario de la Naturaleza Yerba Loca (15\%, Arroyo et al. 2002), el Parque Nacional Río Clarillo (20\%, Teillier et al. 2005), el Santuario de la Naturaleza Palmar El Salto $(24,4 \%$, Flores \& Aguirre 2008) y el Parque Nacional La Campana (14\%, Hauck et al. 2016).

La reducción de las alóctonas silvestres en las unidades de vegetación sobre los $1200 \mathrm{~m}$ de altitud, coincide con la descrito para otras áreas protegidas de Chile (Pauchard \& Alaback 2004; Hauck et al. 2016), donde a mayor altitud se produce un efecto filtro para las especies exóticas debido a condiciones ambientales más adversas tales como una época vegetativa más corta, mayores niveles de radiación ultravioleta, menor temperatura del aire y de las capas de suelo más profundas, presencia de precipitaciones en forma de nieve y mayor frecuencia e intensidad del viento. Por otro lado, su mayor presencia en el matorral xerófilo podría indicar una preferencia local de sitios xéricos y bien iluminados, pero también lugares más bajos y formaciones abiertas, características que coinciden con el territorio ocupado por el ganado.

Para la Región de Valparaíso se han reportado en las laderas de solana hasta unas cincuenta especies alóctonas asilvestradas (Contreras et al. 2011), muchas relacionadas con la regeneración de ambientes sometidos a incendios forestales; también, se ha señalado que las agrupaciones vegetales más ricas en especies se encuentran en las laderas de umbría (Redon 2003). Ambos resultados son similares a los registrados en este estudio.

TABLA 7. Especies del Santuario que alcanzan su límite de distribución nacional en la Región de Valparaíso. / Species of the Sanctuary that reach their national distribution limit in the Valparaiso Region.

\begin{tabular}{|c|c|c|}
\hline ESPECIE & Regiones en Chile & Límite \\
\hline Alstroemeria parvula & VAL a RME & Norte \\
\hline Calceolaria densifolia & VAL a RME & Norte \\
\hline Phycella angustifolia & VAL a RME & Norte \\
\hline Senecio davilae & VAL a RME & Norte \\
\hline Leucheria oligocephala & VAL a LBO & Norte \\
\hline Schinus montanus & VAL a LBO & Norte \\
\hline Blumenbachia dissecta & VAL a MAU & Norte \\
\hline Calceolaria purpurea & VAL a MAU & Norte \\
\hline Leucheria rosea & VAL a MAU & Norte \\
\hline Ourisia serpyllifolia & VAL a MAU & Norte \\
\hline Schinus kauselii & VAL a MAU & Norte \\
\hline Valeriana hornschuchiana & VAL a MAU & Norte \\
\hline Calceolaria thyrsiflora & VAL a BIO & Norte \\
\hline Galium trichocarpum & VAL a BIO & Norte \\
\hline Nassella gibba & VAL a BIO & Norte \\
\hline Ribes polyanthes & VAL a BIO & Norte \\
\hline Calceolaria meyeniana & VAL a ARA & Norte \\
\hline Lathyrus subandinus & VAL a ARA & Norte \\
\hline Valeriana grandifolia & VAL a LRI & Norte \\
\hline Valeriana obtusifolia & VAL a LRI & Norte \\
\hline Vicia nigricans & VAL a AIS & Norte \\
\hline Agrostis inconspicua & VAL a MAG & Norte \\
\hline Calandrinia monandra & VAL a MAG & Norte \\
\hline Escallonia alpina var. carmelitana & VAL a MAG & Norte \\
\hline Nassauvia aculeata & VAL a MAG & Norte \\
\hline Cristaria multiflora & TAR a VAL & Sur \\
\hline
\end{tabular}


Los datos reflejan que el área de estudio posee una baja proporción de especies alóctonas asilvestradas, lo cual podría deberse a que se trata de una cuenca cerrada con un solo dueño, una comunidad agrícola que decidió hace casi veinte años eliminar el ganado caprino y hace más de diez consiguió que la serranía obtuviera la categoría de Santuario de la Naturaleza.

\section{FORMAS DE VIDA}

En relación con las formas de vida, la dominancia en términos de riqueza de las terófitas en la flora del área de estudio es coincidente con los espectros de formas de vida de otros países con clima mediterráneo (Elhaï 1968), aunque a dicha dominancia en el área de estudio concurren significativamente las plantas alóctonas asilvestradas. Al respecto, resulta relevante, sin embargo, que entre las nativas, sea mayor la riqueza de las hemicriptófitas, una forma de vida predominante en los ambientes templados (Elhaï 1968; Braun Blanquet 1979), lo que le daría al área de estudio un carácter más mesofítico que xérico. La mayor riqueza de las especies de terófitas entre las alóctonas asilvestradas en Chile central es un rasgo que se ha registrado en otros estudios en la región mediterránea (Teillier \& Tomé 2004; Hauck et al. 2016).

\section{ABUNDANCIA DE ESPECIES}

La presencia de más de un tercio de especies ocasionales y raras $(101 ; 34,5 \%)$ podría ser explicado, en primer lugar, por el carácter de transición de la zona de estudio en términos bioclimáticos (Di Castri \& Hajek 1976) y geomorfológicos (Börgel 1983), en donde se mezclan elementos de zonas boreales con otros de la zona central e incluso austral, lo que se pone de manifiesto por la presencia de un importante número de especies que alcanzan su límite norte o sur de distribución a nivel nacional en el Santuario, lo que contribuye a explicar también la mayor riqueza de especies a la esperada. En segundo lugar, este porcentaje se podría atribuir al manejo reciente del lugar por parte de la comunidad, en donde decisiones como suprimir el ganado caprino pudieran explicar el resurgimiento de especies escasas o con poblaciones reducidas, las que generalmente son difíciles de catastrar debido a su baja frecuencia local. Específicamente sobre las especies raras, de acuerdo a Rabinowitz (1981) estas responden a tres escalas de análisis; rareza biogeográficas (distribución geográfica), rareza de hábitat (requerimientos de hábitat) y rareza demográfica (tamaño poblaciones locales).

Ejemplos sensibles de estas rarezas son Citronella mucronata y Prosopis chilensis, especies amenazadas que fueron registradas con un solo individuo en el Santuario y que crecen en la zona que fue quemada por el incendio de 2016 que consumió el $65 \%$ de su superficie (CONAF 2016), por lo que su subsistencia en el Santuario no ha sido confirmada.
El aumento en la riqueza de especies de flora vascular registrada en el área, desde las 79 especies totales consideradas al momento de su declaratoria como Santuario el año 2006, donde 59 eran nativas y 27 endémicas, con el paso del tiempo se ha ido incrementando en 98 especies (Galarce \& Trivelli 2013), 125 especies (Flores \& Amigo 2013) al número entregado en este trabajo, el cual alcanzaría al menos a las 293 especies, muestra la necesidad de incluir prospecciones en todas las estaciones del año y aumentar el esfuerzo de muestreo en los trabajos realizados en la ecorregión mediterránea de Chile, debido a la elevada heterogeneidad ambiental imperante, la cual posibilita la existencia de ambientes variados en superficies reducidas.

Elárea del Santuario de la Naturaleza "Serranía El Ciprés" se ha establecido para preservar la diversidad de plantas de Chile mediterráneo y en particular a la población más boreal y altitudinal de Austrocedrus chilensis (Cupressaceae). En este trabajo se caracteriza por primera vez su flora vascular, dando cuenta del registro de 272 especies de flora vascular nativa, un resultado algo mayor que los propuestos por modelos especie/área para Chile central; a esta diversidad se suma el importante grado de naturalidad, pues apenas un $7,2 \%$ de las especies son alóctonas asilvestradas.

La calidad de Santuario considera la presencia de al menos diez especies en categoría de conservación, entre las vulnerables: Citronella mucronata, Eriosyce aurata, Placea ornata, Porlieria chilensis y Prosopis chilensis. Entre las casi amenazadas están, Austrocedrus chilensis, Kageneckia angustifolia, Pellaea myrtillifolia, Solaria miersioides y Trichocereus chiloensis.

No obstante, y pese a su condición de Santuario, algunas actividades amenazan su conservación, en primer lugar, la ganadería no ha sido del todo suprimida y se mantiene en la actualidad la incorporación de ganado durante el invierno y primavera en las partes bajas y en verano en las zonas altas, actividad que ha erosionado fuertemente el Santuario. Por otra parte, la actividad minera representa una amenaza para el Santuario, ya que incluso en su interior se desarrolla extracción de mineral, representando una dificultad para el manejo del Santuario por parte de la comunidad. Todo esto sumado al riesgo de incendios forestales.

Los datos expuestos constituyen un aporte al conocimiento de la flora vascular de la cuenca de Aconcagua, zona intervenida principalmente por la expansión de la frontera agrícola, por lo que contar con información a escala local contribuirá a mejorar la toma de decisiones, especialmente para considerar en el proceso de restauración.

\section{AGRADECIMIENTOS}

Se agradece a la Comunidad Agrícola Serranía El Asiento por permitirnos el ingreso y muestreo de su predio. A la Corporación CIEM Aconcagua, quienes a través de sus 
proyectos hicieron posible una parte de las campañas de terreno. A Odfjell Vineyards por su contribución para llevar adelante esta publicación. A Nicolás Garcia por su ayuda en la identificación de las especies de la familia Amaryllidaceae. A los revisores anónimos por sus comentarios. Los primeros autores agradecen especialmente a Verónica, Felipe, Belén y Garúa por su constante apoyo a lo largo de esta investigación.

\section{REFERENCIAS}

APG IV. 2016. An update of the Angiosperm Phylogeny Group classification for the orders and families of flowering plants: APG IV. Botanical Journal of the Linnean Society 181: 1-20. The Angiosperm Phylogeny Group.

Arroyo, M.T.K., Cavieres, L. 1997. The Mediterranean-type climate flora of central Chile - What do we know and how can we assure its protection?. Noticiero de Biología (Chile) 5: 48-56.

Arroyo, M.T.K., Rozzi, R., Simonetti, J., Marquet, P., Salaberry, M. 1999. Central Chile. In: RA Mittermeier, N Myers \& CG Mittermeier (eds.). Hotspots: Earth's biologically richest and most endangered terrestrial ecosystems, pp. 161-171. CEMEX, México, Distrito Federal.

Arroyo, M.T.K., Marticorena, C., Matthei, O., Muñoz-Schick, M., Pliscoff, P. 2002. Analysis of the contribution and efficiency of the Santuario de la Naturaleza Yerba Loca, $33^{\circ} \mathrm{S}$ in protecting the regional vascular plant flora (Metropolitan and Fifth Regions of Chile). Revista Chilena de Historia Natural. 75: 767-792.

Aschmann, H., Bahre, C.J. 1977. Man's impact on the wild landscape. En Mooney, H.A. Ed. Convergent evolution in Chile and California Mediterranean climate ecosystem. Dowden, Hutchinson \& Ross, Stroudsburg, Pennsylvania, USA. 73-84.

Blackhall, M., Raffaele, E., Veblen., T.T. 2015. Efectos combinados del fuego y el ganado en matorrales y bosques del noroeste patagónico. Ecología Austral 25:1-10.

Börgel, R. 1983. Geomorfología de Chile, Tomo II. Colección Geografía de Chile. Santiago, Instituto Geográfico Militar de Chile.

Braun-Blanquet, J. 1979. Fitosociología, bases para el estudio de las comunidades vegetales. Blume, Madrid. $820 \mathrm{pp}$.

Botanical Society of Britain \& Ireland. s.f. Guidance notes for recording DAFOR scores. URL: http://www.botanicalkeys. co.uk/northumbria/dafor.asp Accedido: Julio 22, 2013.

Castro, C.P., Maerker, M., Aliaga, C. 2010. Evaluación de la pérdida de suelo, asociada al proceso de expansión urbana y reconversión productiva. Caso: Comunas de los Andes, Quillota y Concón, Valle del Aconcagua. Revista de geografía Norte Grande 45: 41-49.

Ciren. 1997. Estudio Agrológico V Región. Descripciones de suelos, materiales y símbolos. Centro de Información de Recursos Naturales. Santiago, Chile. 392 pp.

Conaf. 2016. Corporación Nacional Forestal. http://www.conaf. $\mathrm{cl} /$ conaf-confirma-que-incendio-afecto-solo-al-10-decipreses-milenarios.

Conama - Pnud. 2005. Estrategia Regional y Plan de Acción para la Conservación de la Diversidad Biológica, Región de Valparaíso, Chile. Comisión Nacional del Medio Ambiente - Programa de las Naciones Unidas para el Desarrollo. 239 pp.

Contreras, T.E., Figueroa, J.A., Abarca, L., Castro, S.A. 2011. Fire regimen and spread of plants naturalized in central Chile. Revista Chilena de Historia Natural. 84(3): 307-323.

Corporación Ciem Aconcagua. 2004. Estudio de 3 Ecosistemas patrimoniales relevantes en el valle del Aconcagua. Proyecto financiado por Fundación Avina. San Felipe, Chile.

Corporación Ciem Aconcagua. 2006. Gestión Local Sustentable Serranía del Ciprés. Proyecto financiado por PPS del PNUD. San Felipe, Chile.

Corporación Ciem Aconcagua. 2008. Santuario de la Naturaleza Serranía del Ciprés. Ediciones Almendral. San Felipe, Chile. 139 pp.

Corporación Ciem Aconcagua. 2014. Conservación comunitaria en Aconcagua. Proyecto financiado por The Nature Conservancy. San Felipe, Chile.

Corporación Ciem Aconcagua. 2017. Restauración ecológica del Santuario de la Naturaleza Serranía del Ciprés. Proyecto financiado por FPA del MMA. San Felipe, Chile.

Cowling, R.M., Rundel, P.W., Lamont, B.B., Arroyo, M.T.K., Arianoutsou, M. 1996. Plant diversity in mediterranean climate regions. Trends in Ecology and Evolution 11: 362366.

Cunill, P. 1970. Factores en la destrucción del paisaje chileno: recolección, caza y tala coloniales. Universidad de Chile, Santiago, Chile. Informaciones Geográficas, número especial: 235-264.

Del Campo, P. 2005. Datos sin publicar. Flora, Vegetación y Paisaje de la Quebrada El Asiento y Cerro Tabaco. Corporación CIEM Aconcagua. Documento Interno. San Felipe, Chile.

Di Castri, F., Hajek, E.R. 1976. Bioclimatología de Chile. Ed. PUC Chile. Santiago, Chile. 128 pp.

Elhaï, H. 1968. Biogéographie. Librairie Armand Colin, París.

Flores-Toro, L., Aguirre-Sanvedra, F. 2008. Riqueza florística del Santuario de la Naturaleza Palmar El Salto, Comuna de Viña del Mar, Región de Valparaíso, Chile. Gayana Botánica 65(1): 1-13.

Flores-Toro, L., Amigo, J. 2013. Flora autóctona de la cordillera El Melón y del cerro Tabaco, sitios prioritarios para la conservación de la biodiversidad, Región de Valparaíso, Chile. Chloris Chilensis 16(1). URL: http://www. chlorischile.cl

Fuentes, E.R., HajeK, E.R. 1979. Patterns of landscape modification in relation to agricultural practice in Central Chile. Environmental Conservation 6: 265-271.

Fuentes, N., Pauchard, A., SÁnchez, P., Esquivel, J., Marticorena, A. 2013. A new comprehensive database of alien plant species in Chile based on herbarium records. Biological Invasions 15(4): 847-858.

Gajardo, R. 1994. La vegetación natural de Chile, clasificación y distribución geográfica. Editorial Universitaria. Santiago, Chile. 165 pp.

Gajardo, R., Serra, M., Grez, I. 1987. Fichas técnicas de lugares específicos con presencia de especies leñosas amenazadas de extinción. Programa de Protección y Recuperación de la Flora Nativa de Chile. Corporación Nacional Forestal, CONAF. 
Galarce, G., Trivelli, M. 2013. Reseña sobre Flora y Vegetación de la Serranía El Asiento, San Felipe, Región de Valparaíso. 118 pp. Servicio Agrícola y Ganadero, SAG.

Hauck, L., Moreira-Muñoz, A., NeZADA, W. 2016. La flora exótica ruderal del Parque Nacional La Campana, Región de Valparaíso, Chile central. Gayana Botánica 73(2): 206-219.

Hechenleitner, P., Gardner, M., Thomas, P., Echeverría, C., Escobar, B., Brownless, P., Martínez, C. 2005. Plantas Amenazadas del Centro-Sur de Chile. Distribución, Conservación y Propagación. Primera Edición. U. Austral de Chile y Real Jardín Botánico de Edimburgo. 188 pp.

Holmgren, M., Avilés, M.R., Sierralta, L., Segura, A.M., FuENTES, E.R. 2000. Why have European herbs so successfully invaded the Chilean matorral? Effects of herbivory, soil nutrients, and fire. Journal of Arid Environments 44: 197-211.

INE. 2017. Medio Ambiente. Informe Anual 2017. Instituto Nacional de Estadísticas. Santiago, Chile. 206 pp.

JBN. 2008. Hallazgo de Adesmia rubroviridis Burkart. Dendroseris. Año 1, №1: 1-1. Boletín del Jardín Botánico Nacional.

Judd, W.S., Campbell, C.S., Kellogg, E.A., Stevens, P.F., Donoghue, M.J. 2008. Plant Systematics: A Phylogenetic Approach, 3rd edition. Sinauer Associates, Massachusetts, USA. $611 \mathrm{pp}$.

LaMarche, V.C., Holmes, R.L., Donwiddie, P.W., Drew, LG. 1979. Chile. Tree-Ring Chronologies of the Southern Hemisphere Series V. Vol. 2. Laboratory of Tree-Ring Research. University of Arizona, USA. 43 pp.

Le Quesne, C., Acuña, C., Boninsegna, J., Rivera, A., Barichivic, J. 2009. Long-term glacier variations in the Central Andes of Argentina and Chile, inferred from historical records and tree-ring reconstructed precipitation. Paleogeography, Palaeoclimatology, Palaeoecology 281: 334-344.

Le Quesne, C., Rojas, M., Christie, D. 2014. Anillos de crecimiento de Austrocedrus chilensis: un archivo natural del cambio climático. Revista Chagual 12: 31-35.

Le Quesne, C., Stahle, D.W., Cleaveland, M.K., Therrell, M.D., Aravena, J.C., Barichivich, J. 2006. Ancient Austrocedrus tree-ring chronologies use to reconstruct Central Chile precipitation variability from A.D. 1200 to 2000. Journal of Climate 19: 5731-5744.

Luebert, F., Gajardo, R. 2004. Antecedentes sobre la vegetación de la cordillera de los Patos, Andes de Chile central (Región de Valparaíso, V). Chloris Chilensis 7(2). URL: http://www.chlorischile.cl.

Luebert, F., Muñoz-Schick, M., Moreira-Muñoz, A. 2002. Vegetación y flora de La Campana. En: S. Elórtegui y A. Moreira (eds.), Parque Nacional La Campana. Origen de una Reserva de la Biosfera en Chile central, pp. 36-69. Taller La Era - Fondo de las Américas, Santiago, Chile.

Luebert, F., Pliscoff, P. 2006. Sinopsis bioclimática y vegetacional de Chile. Editorial Universitaria, Santiago, Chile. 307 pp.

Luebert, F., Pliscoff, P . 2012. Variabilidad Climática y Bioclimas de la Región de Valparaíso, Chile. Investigaciones Geográficas 44: 41-56.

Madrid, A. 2005. Estructura, Dinámica y Estado de Conservación del rodal de Austrocedrus chilensis. Quebrada El Asiento, V Región. Monografía de Grado. Escuela de Ecología y Paisaje, Universidad Central. Santiago, Chile. 67 pp.
MAdrid, A. 2006. Planificación del Paisaje y Proyecto: Quebrada el Asiento, San Felipe, V Región. Proyecto de Título. Escuela de Ecología y Paisaje, Universidad Central. Santiago, Chile. 58 pp.

Marticorena, C. 1990. Contribución a la estadística de la flora vascular de Chile. Gayana Botánica 47(3-4): 85-113.

Marticorena, C., Rodríguez, R. 1995. Flora de Chile. Vol. 1. Pteridophyta-Gymnospermae. 351 pp. Universidad de Concepción. Chile.

Marticorena, C., Rodríguez, R. 2001. Flora de Chile. Vol 2. Winteraceae-Ranunculaceae. 99 pp. Universidad de Concepción. Chile.

Marticorena, C., Rodríguez, R . 2003. Flora de Chile. Vol 2 (2). Berberidaceae-Betulaceae. 93 pp. Universidad de Concepción. Chile.

Marticorena, C., Rodríguez, R . 2005. Flora de Chile. Vol 2 (3). Plumbaginaceae-Malvaceae. 127 pp. Universidad de Concepción. Chile.

Marticorena, C., Rodríguez, R . 2011. Flora de Chile. Vol 3 (1). Misodendraceae-Zygophyllaceae 148 pp. Universidad de Concepción. Chile.

Marticorena, C., Squeo, F.A., Arancio, G., Muñoz-Schick, M. 2001. Catálogo de la flora vascular de la IV Región de Coquimbo. En: F.A. Squeo, G. Arancio \& J.R. Gutiérrez (eds.) Libro Rojo de la flora nativa y de los sitios prioritarios para su conservación: Región de Coquimbo. 7: 105-142. Eds. Universidad de La Serena, Chile.

Matthei, O. 1995. Manual de las malezas que crecen en Chile. Alfabeta Impresores. Santiago. 545 pp.

Minsegrees - Conama. 2006-2009. Aprueba y oficializa Clasificación de especies según su estado de conservación, Primero a Cuarto Procesos. Ministerio Secretaría General de la Presidencia - Comisión Nacional del Medio Ambiente.

MMA. 2011-2016. Aprueba y oficializa Clasificación de especies según su estado de conservación, Quinto a Duodécimo Procesos. Ministerio del Medio Ambiente.

MMA - GEF. 2016. Diagnóstico y Caracterización de las Iniciativas de Conservación Privada en Chile. Ministerio del Medio Ambiente y Fondo para el Medio Ambiente Mundial. 174 pp.

MMA. 2018. Registro Nacional de Áreas Protegidas. URL: http:// bdrnap.mma.gob.cl/buscador-rnap/\#/busqueda? $p=10$ Accedido: Febrero, 19, 2018.

MuÑoz-SCHICK, M., NúÑEz, H., YÁÑEz, J. (EDS.). 1996. Libro rojo de los sitios prioritarios para la conservación de la diversidad biológica en Chile. CONAF, Santiago, Chile.

Myers, N., Mittermeier, R.A., Mittermeier, C.G., Da Fonseca, G.A.B., Kent, J. 2000. Biodiversity hotspots for conservation priorities. Nature 403: 853-858.

Novoa, P., Matus, M. 2013. Flora de la Región de Valparaíso: Patrimonio y Estado de Conservación. Ed. Fundación Jardín Botánico Nacional. 360 pp.

Parra, B., Pichuantes, S. 1981. Pteridofitos del valle de Putaendo. Anales del Museo de Historia Natural de Valparaíso 14: 57-70.

Pauchard, A., Alaback, P.B. 2004. Influence of Elevation, Land Use, and Landscape Context on Patterns of Alien Plant Invasions along Roadsides in Protected Areas of SouthCentral Chile. Conservation Biology 18: 238-248. 
Peralta, P., Múlgura de Romero, M.E., Denham, S.S., Botta, S.M. 2008. Revisión del género Junellia (Verbenaceae). Annals of the Missouri Botanical Garden 95(2): 338-390.

Quintanilla, V.G. 1978. El escalonamiento vegetal de los Andes Occidentales a la latitud de Valparaíso $\left(33^{\circ} \mathrm{S}\right)$. Informaciones Geográficas 25: 53-66.

Quintanilla, V.G. 2014. Los impactos de los incendios forestales en los bosques esclerófilos costeros mediterráneos de Chile. Caso de la Región de Valparaíso. Territorium 21: 125-134.

Rabinowitz, D. 1981. Seven forms of rarity. In: Synge, H. (Ed.). The Biological Aspects of Rare Plant Conservation. pp. 205-217. John Wiley \& Sons Ltd.

Raunkiaer, C. 1934. The Life Forms of Plants and Statistical Plant Geography. Clarendon Press, Oxford. 632 pp.

REDON, J. 2003. Flora y vegetación de la cuenca del Estero de Viña del Mar. Quinta Región. Chile. Cuadernos de Investigación 2: 1-60. Universidad de Viña del Mar.

RodríGuEZ, R. 1986. Die chilenischen Arten der Gattung Sisyrinchium L. (Iridaceae). Mitteilungen der Botanischen Staatssammlung München 22: 97-201.

Schlegel, F.M. 1962. Hallazgo de un bosque de cipreses cordilleranos en la provincia de Aconcagua. Boletín de la Universidad de Chile 32: 43-46.

Sernageomin. 2012. Atlas de Faenas Mineras, Regiones de Valparaíso, del Libertador General Bernardo O’Higgins y Metropolitana de Santiago (Versión Actualizada). Servicio Nacional de Geología y Minería. Mapas y Estadísticas de Faenas Mineras de Chile N². Santiago, Chile. 177 pp.

Teillier, S., Aldunate, G., Riedemann, P., Niemeyer, H. 2005. Flora de la Reserva Nacional Río Clarillo. Guía de identificación de especies. Impresos Socías Ltda. Santiago, Chile. 367 pp.

Teillier, S., Hoffmann, A., SaAvedra, F., Pauchard, L. 1994. Flora del Parque Nacional El Morado (Región Metropolitana, Chile). Gayana Botánica 51(1): 13-47.

Teillier, S., Tomé, A. 2004. Contribución al conocimiento de la flora de la cuenca de la quebrada de Ramón. Región Metropolitana, Chile. Boletín del Museo Nacional de Historia Natural de Santiago 53: 17-36.

Zuloaga, F.O., Morrone, O., Belgrano, M.J. (eds.). 2008. Catálogo de las Plantas Vasculares del Cono Sur (Argentina, Sur de Brasil, Chile, Paraguay y Uruguay). URL: http:// www.darwin.edu.ar/Proyectos/FloraArgentina/FA.asp Accedido: Julio 21, 2017. 


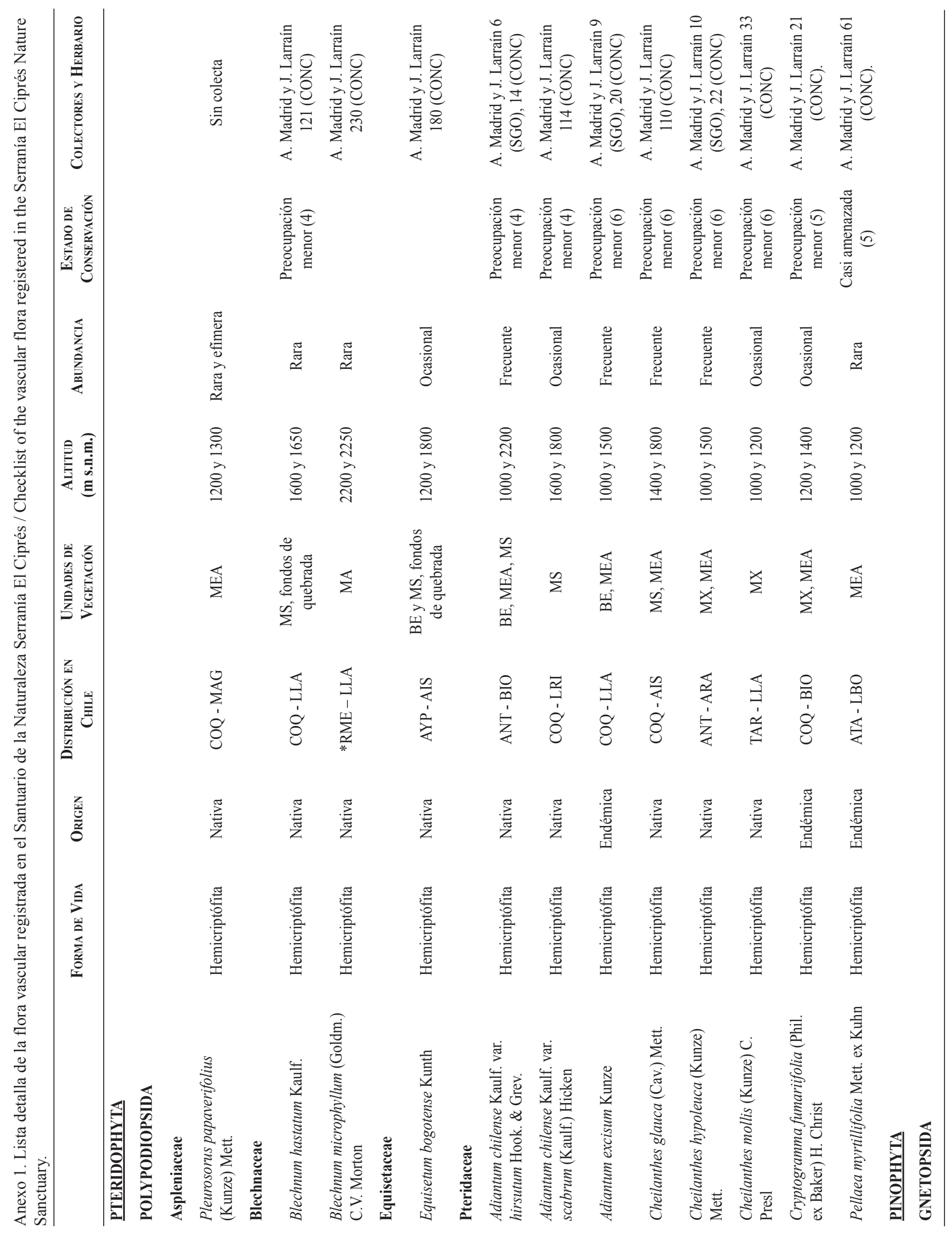




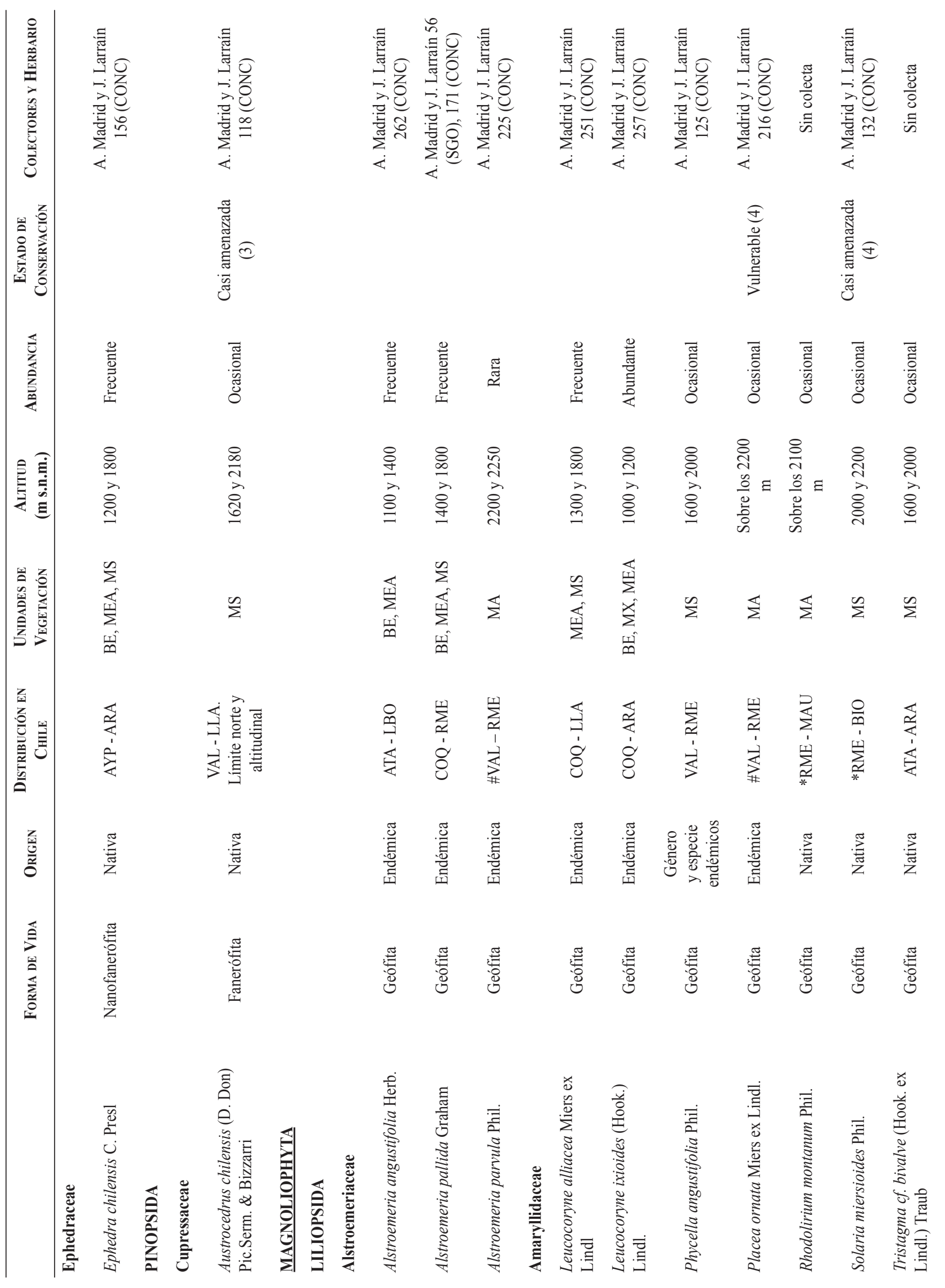




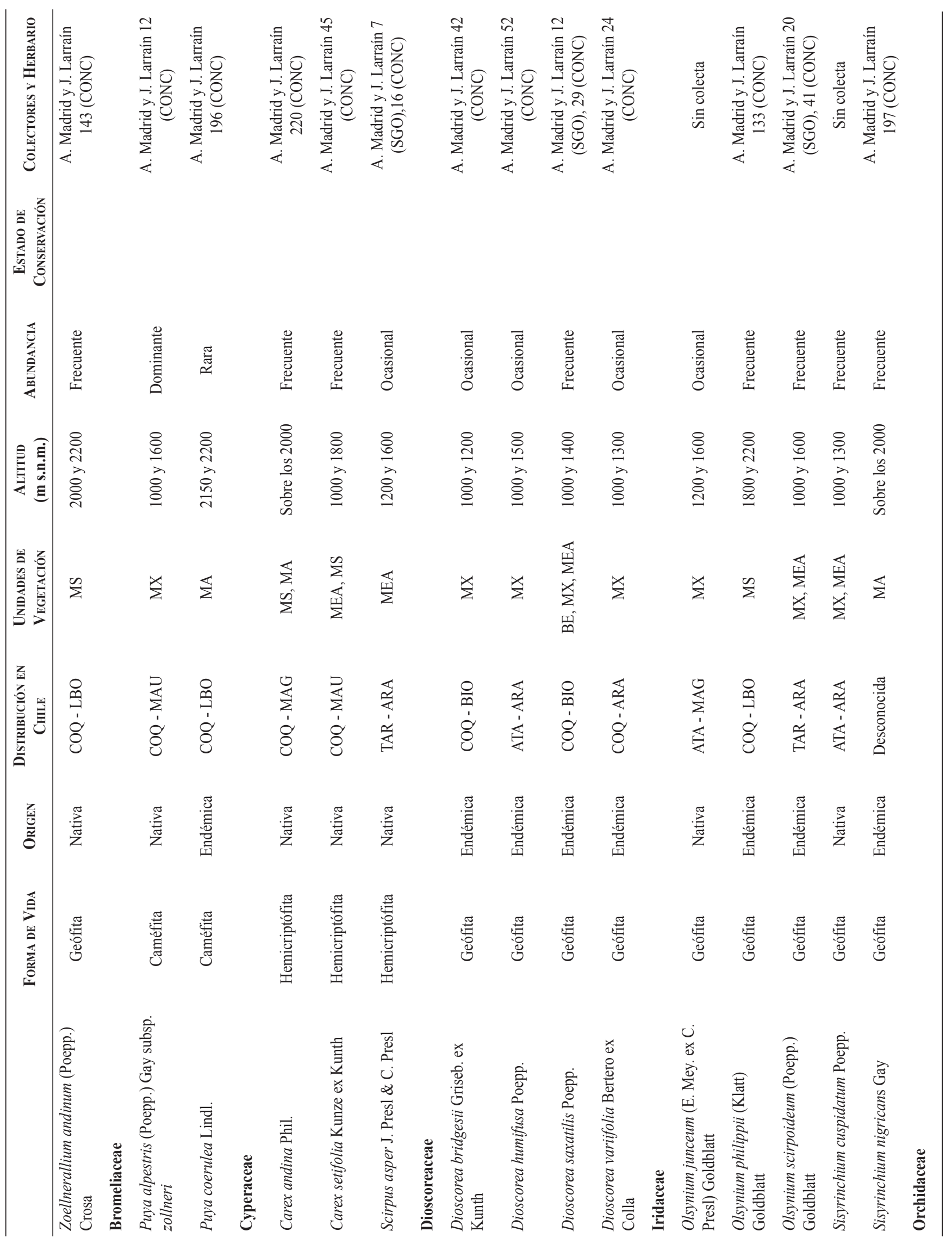




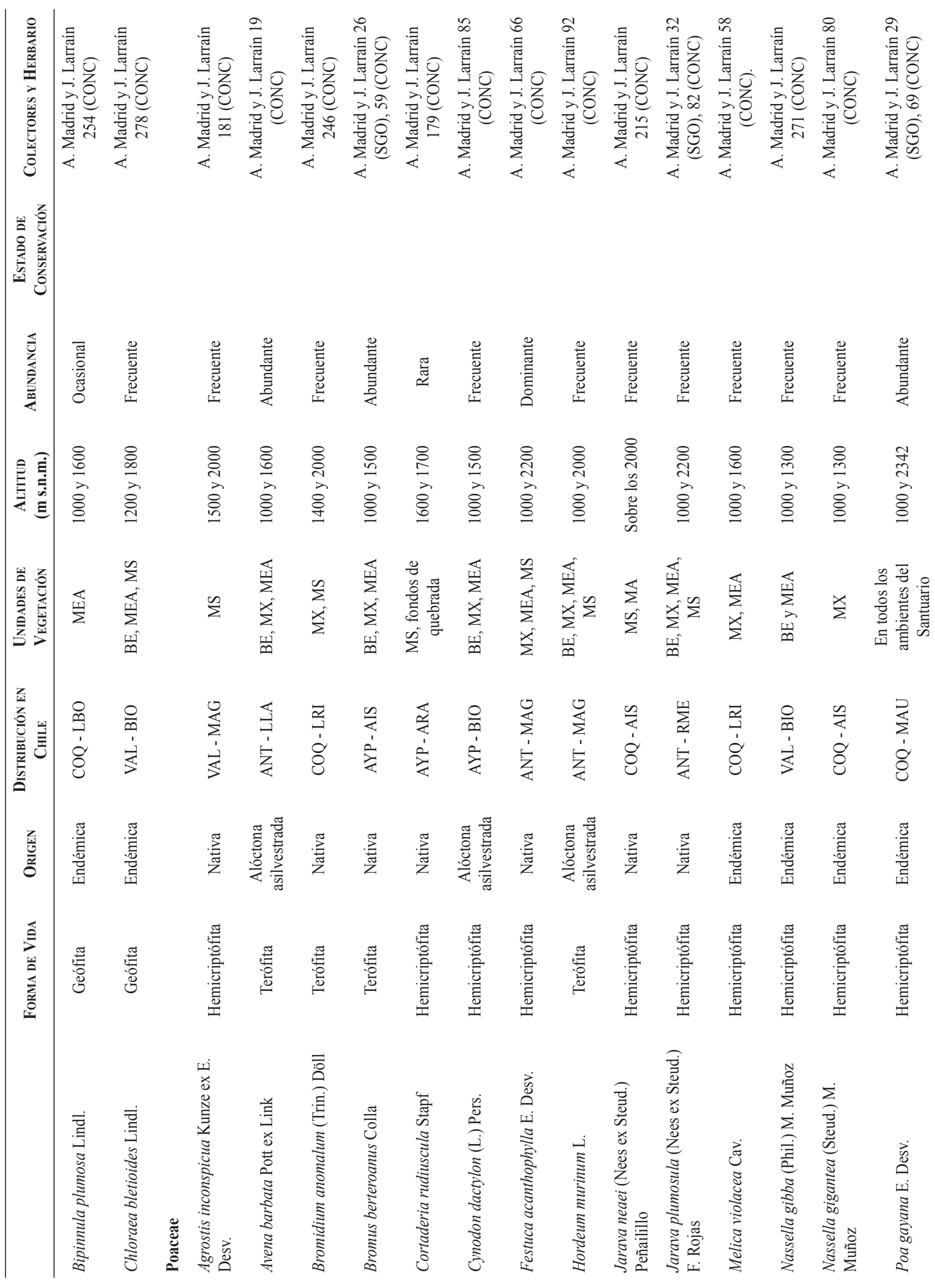




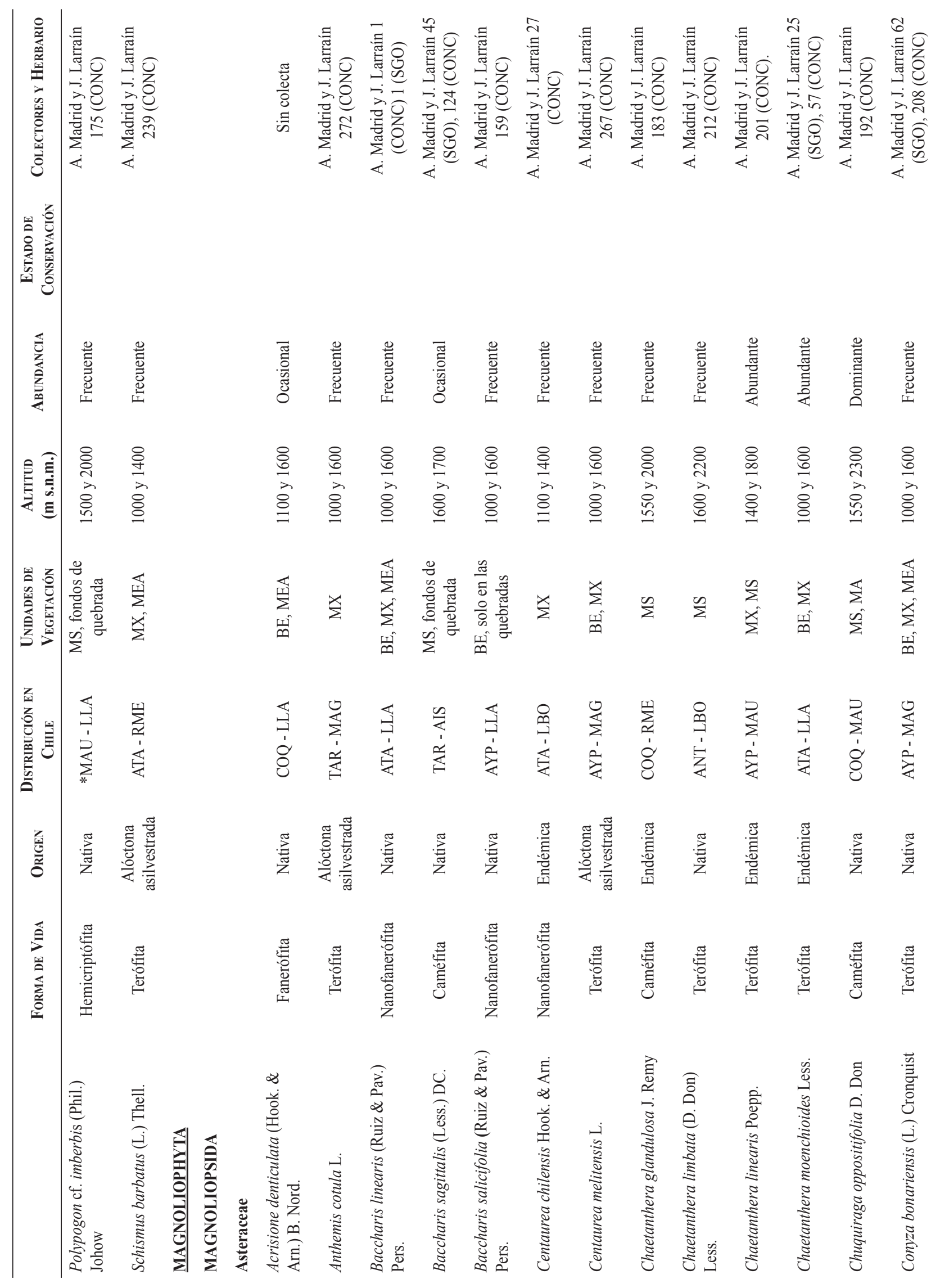




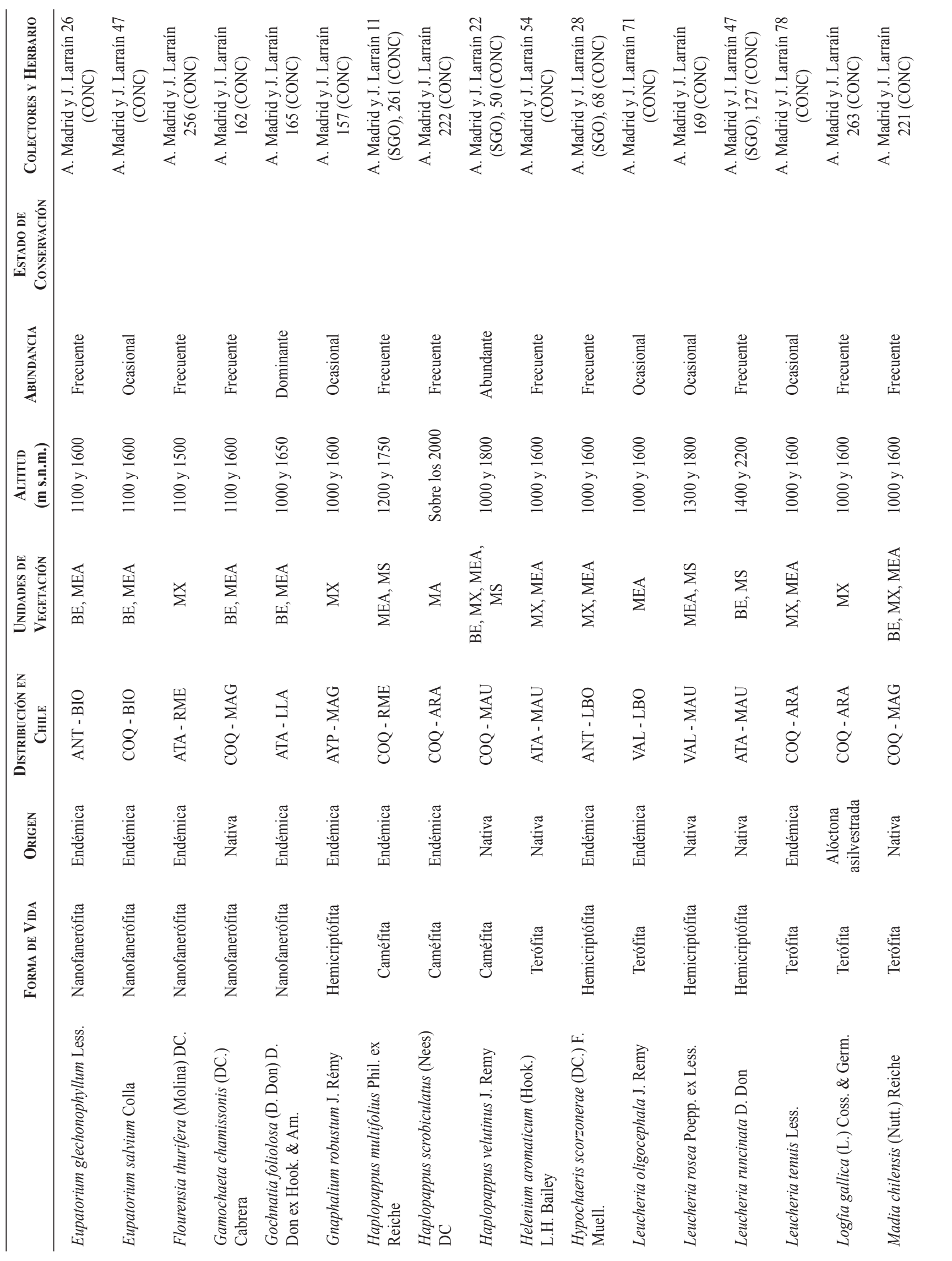




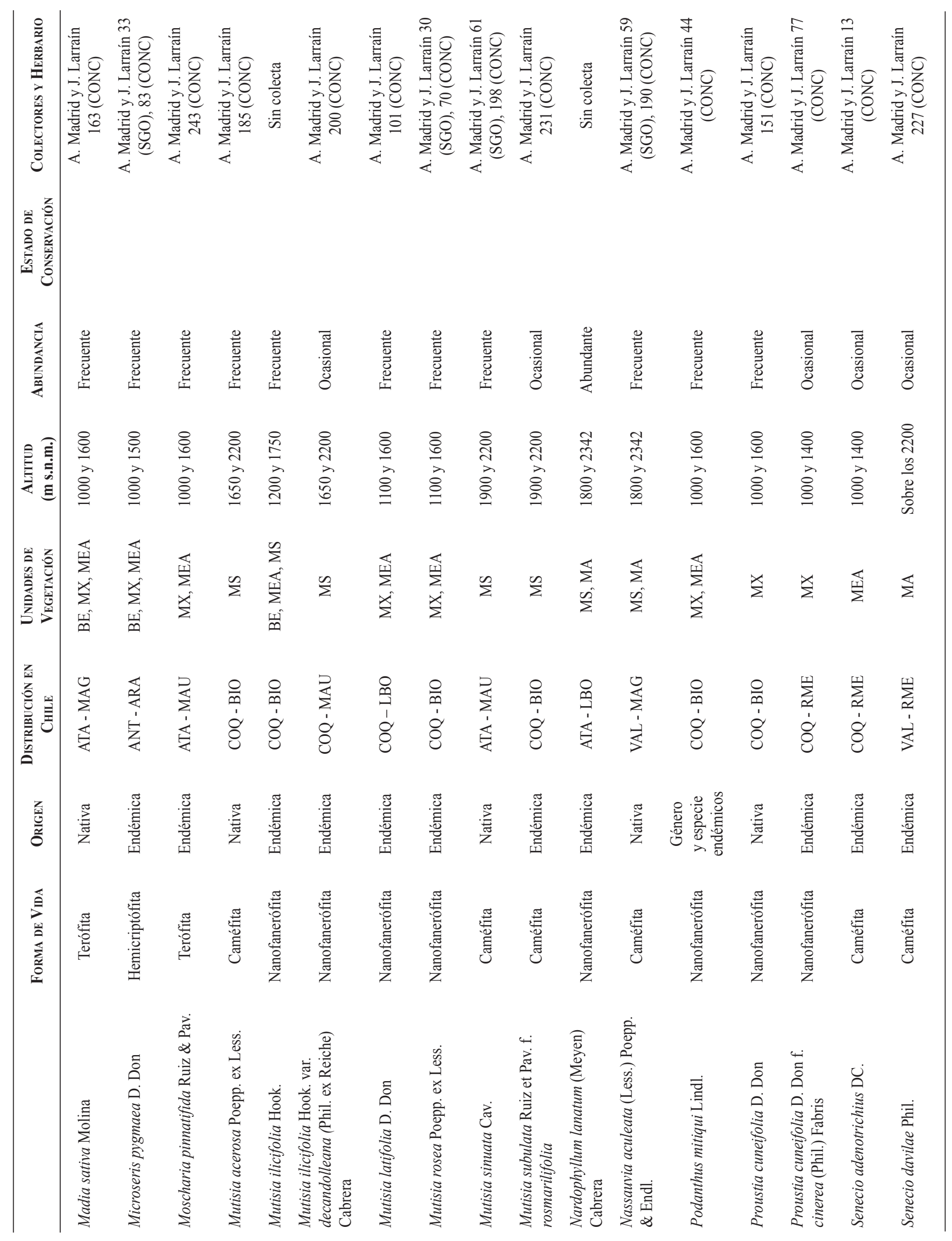




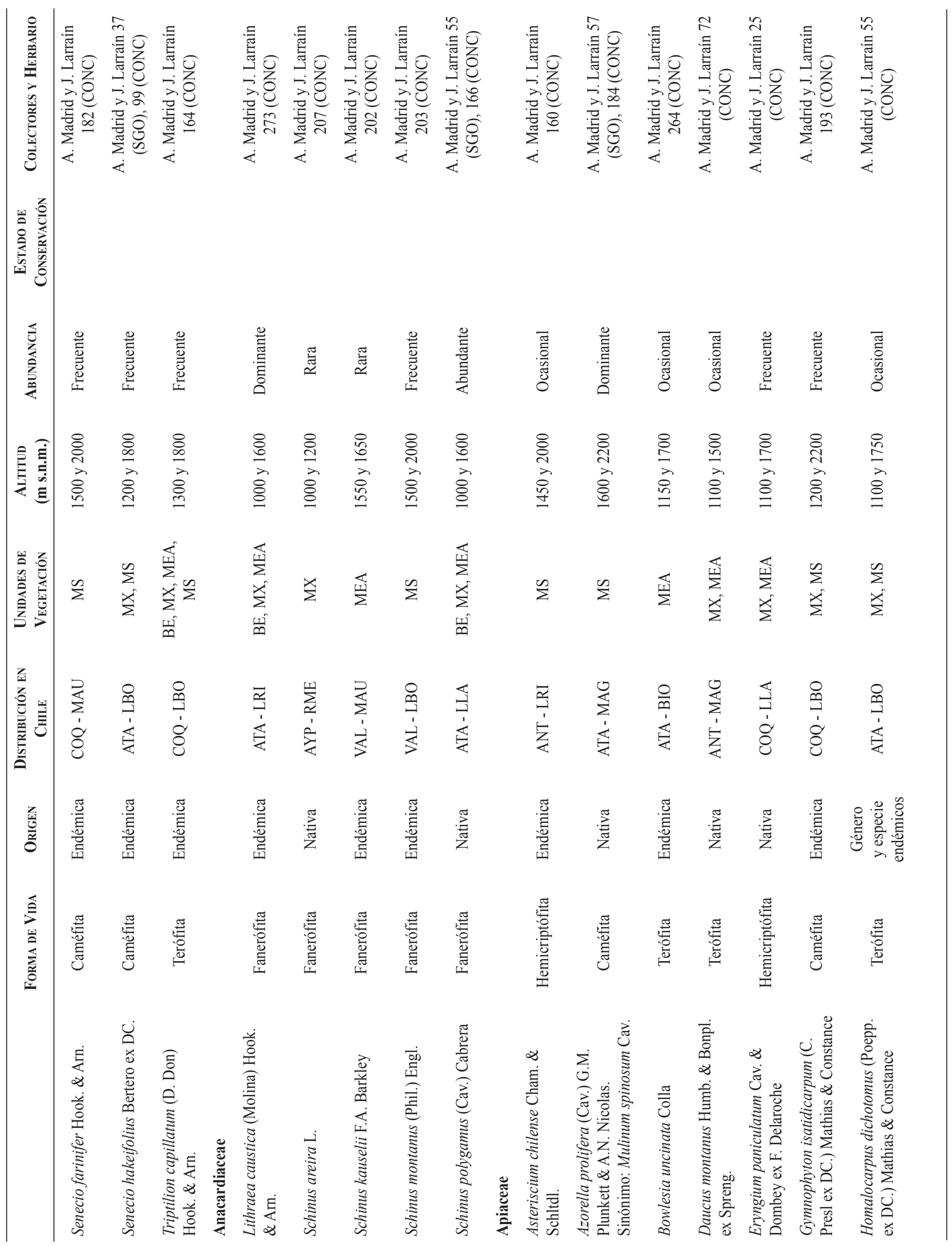




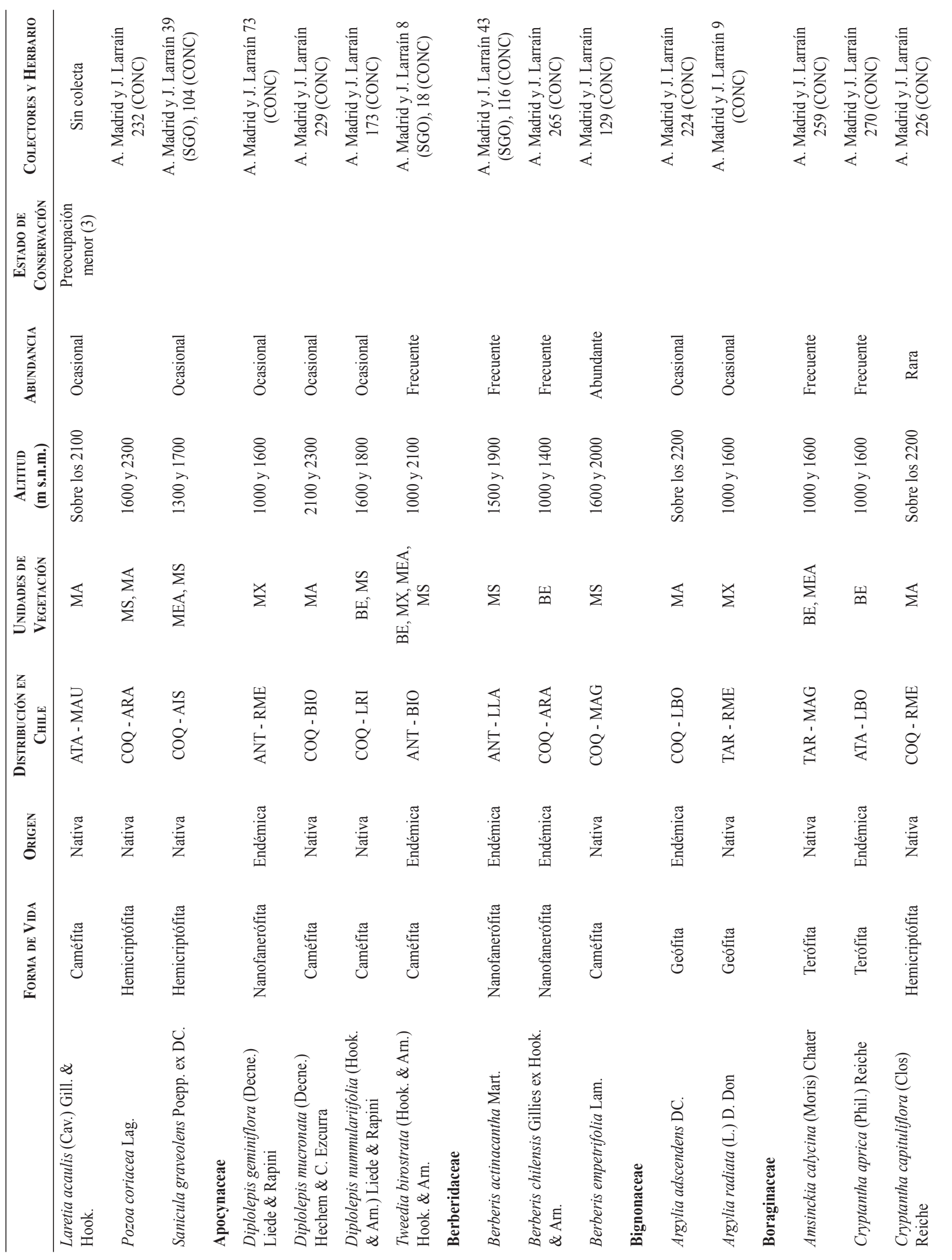




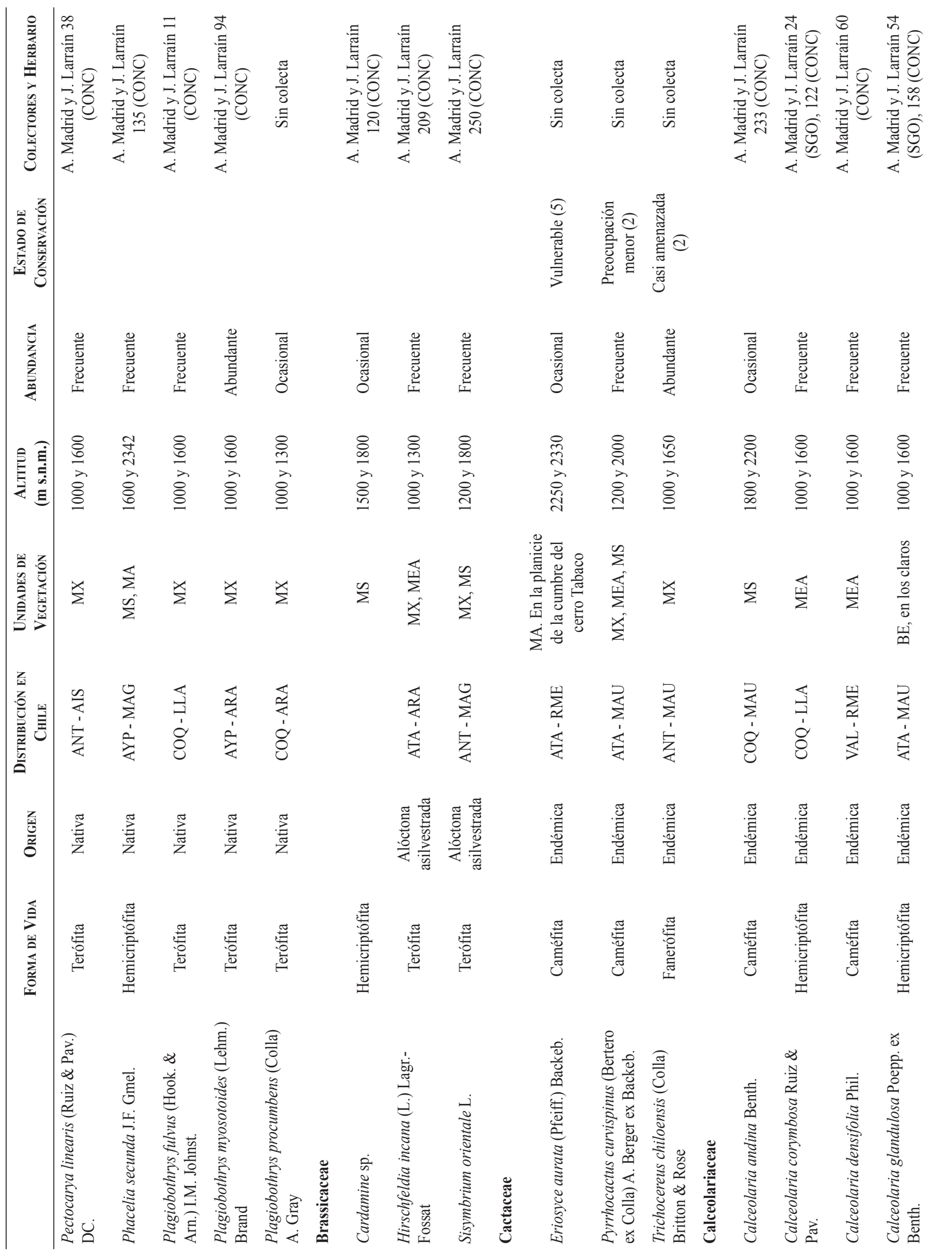




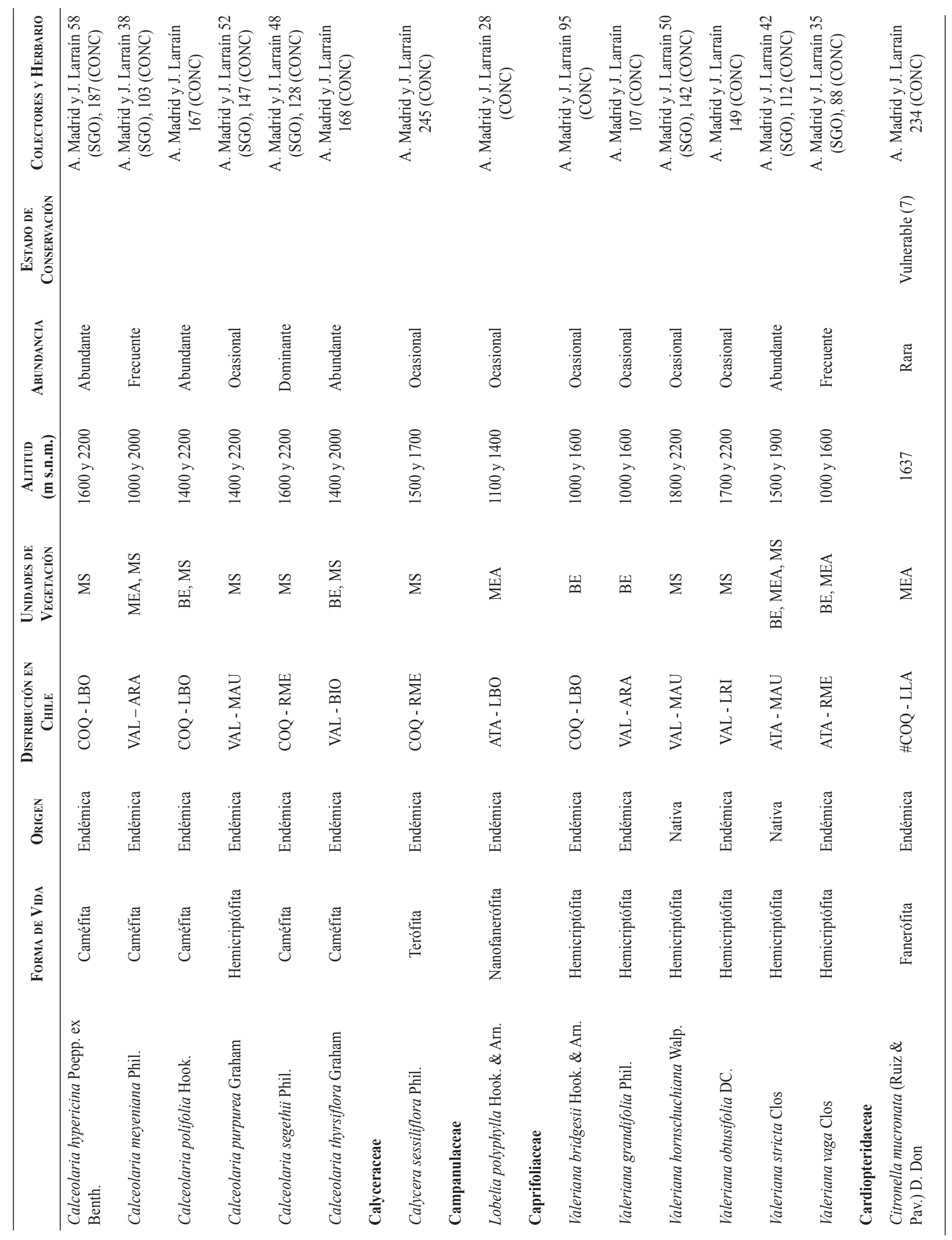




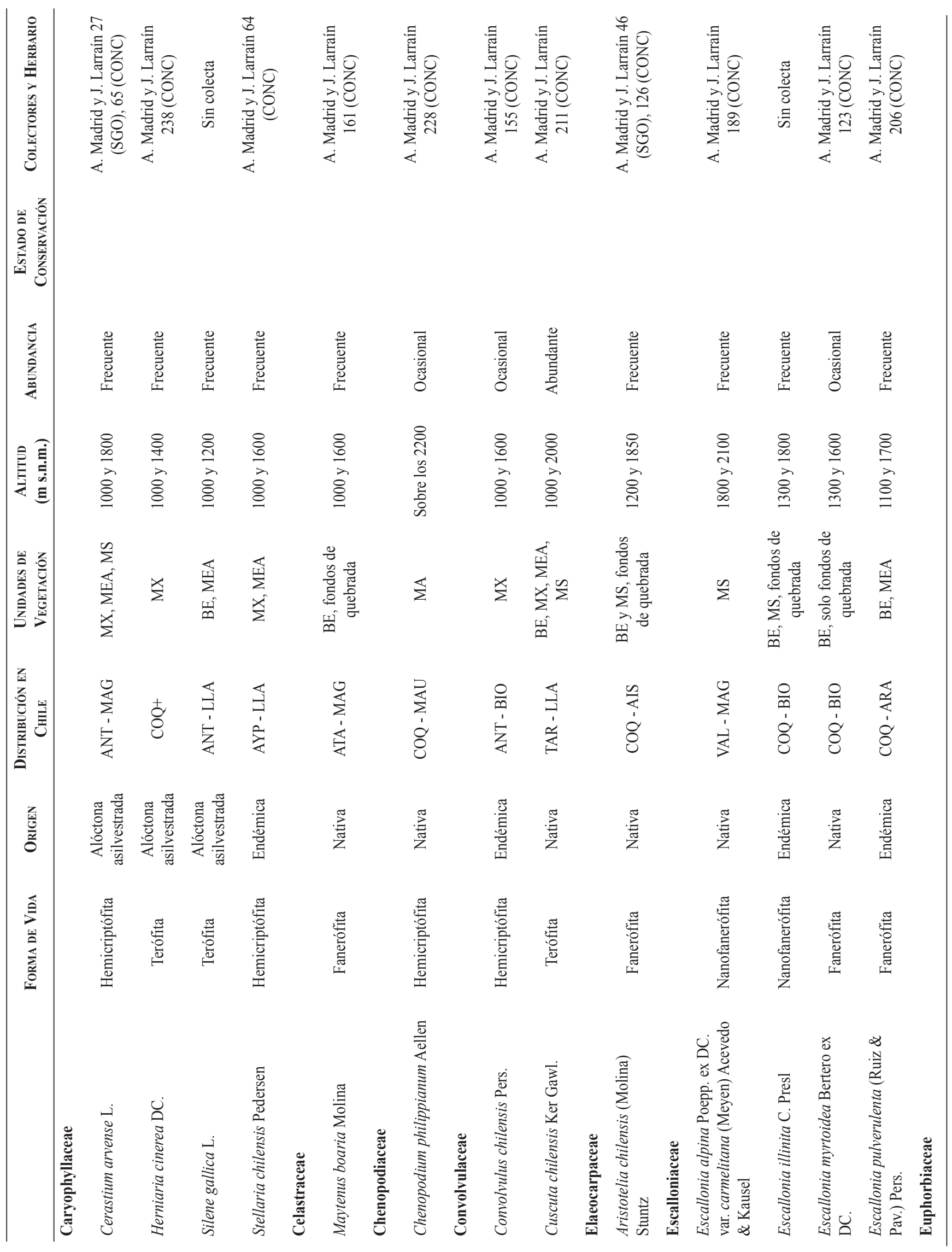




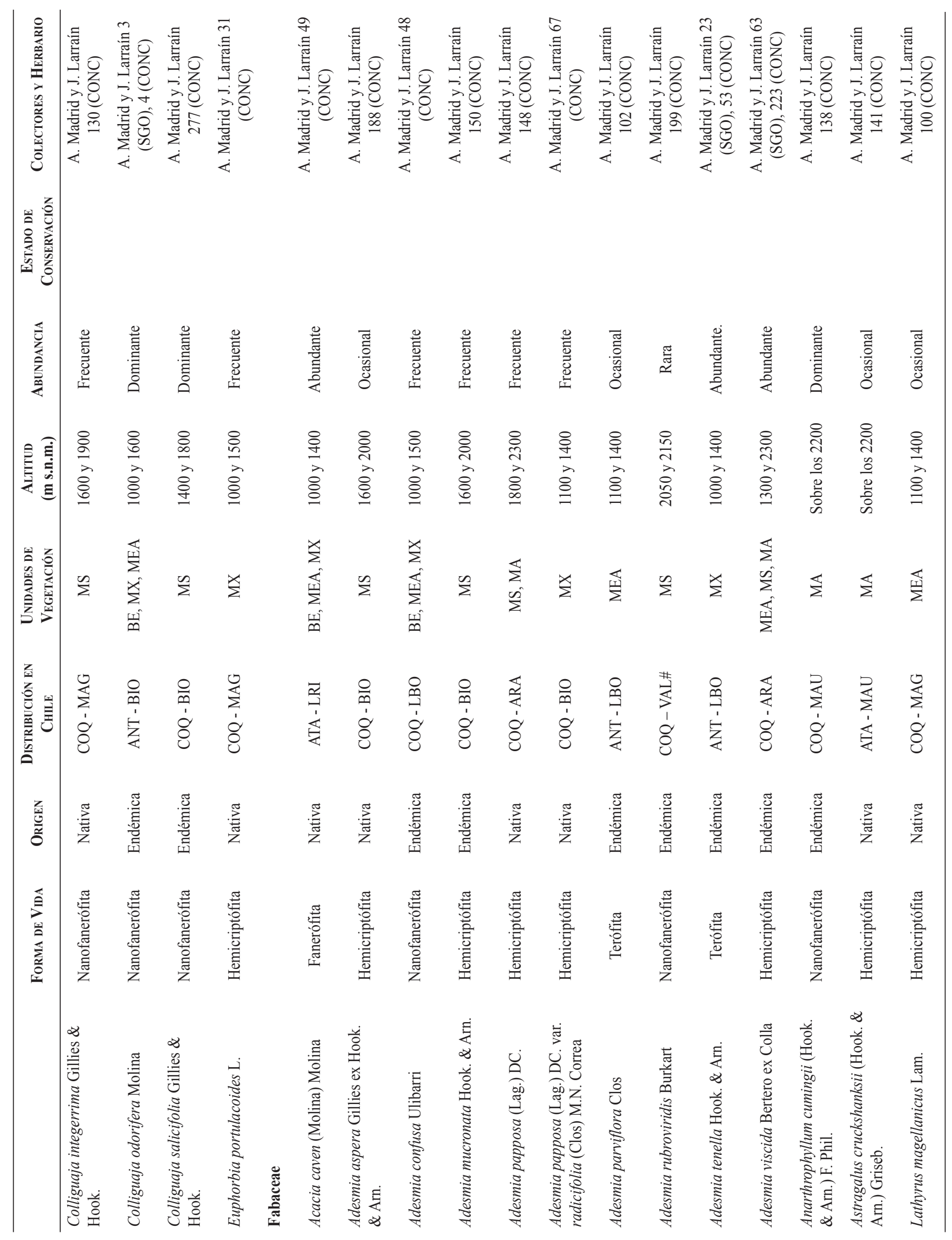




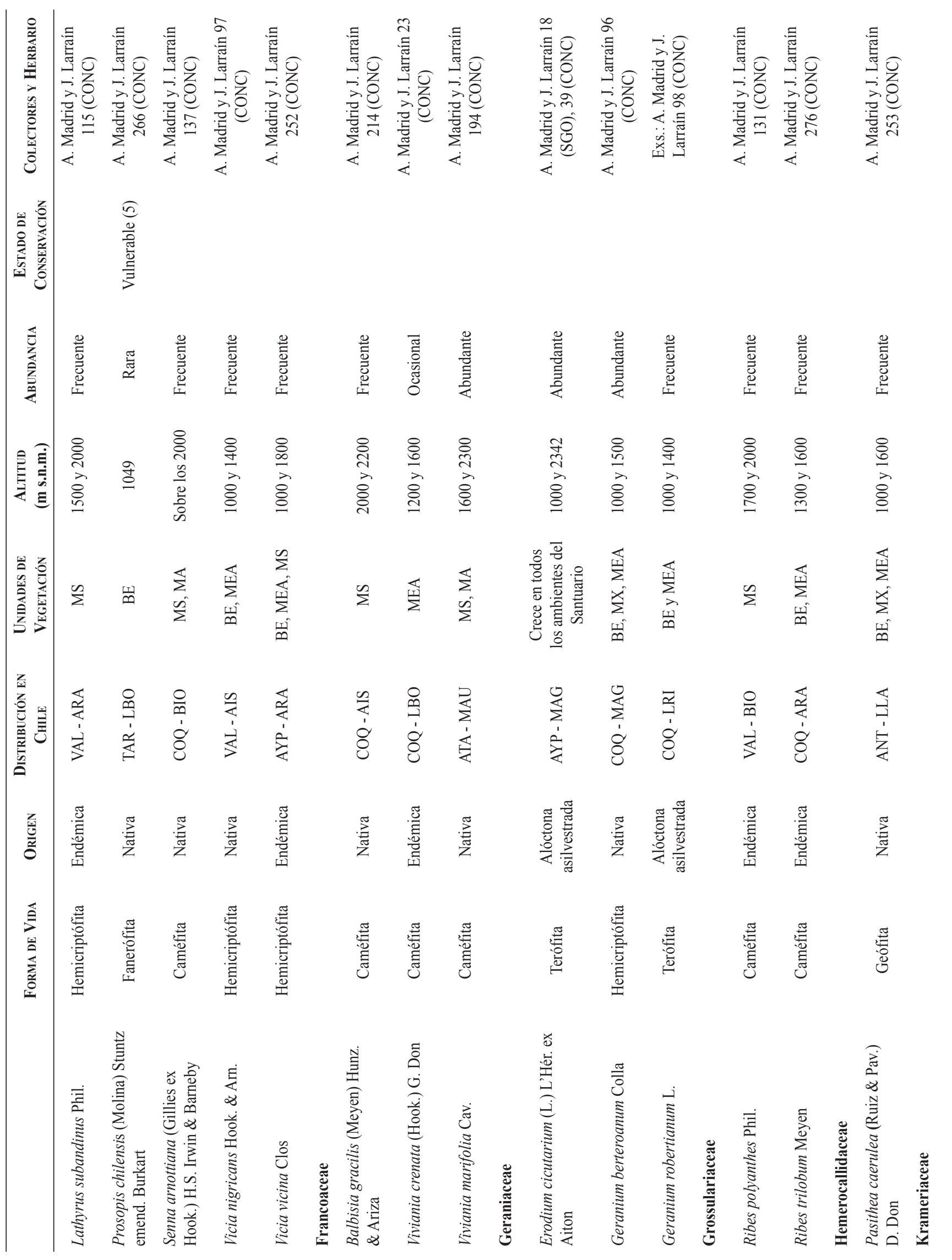




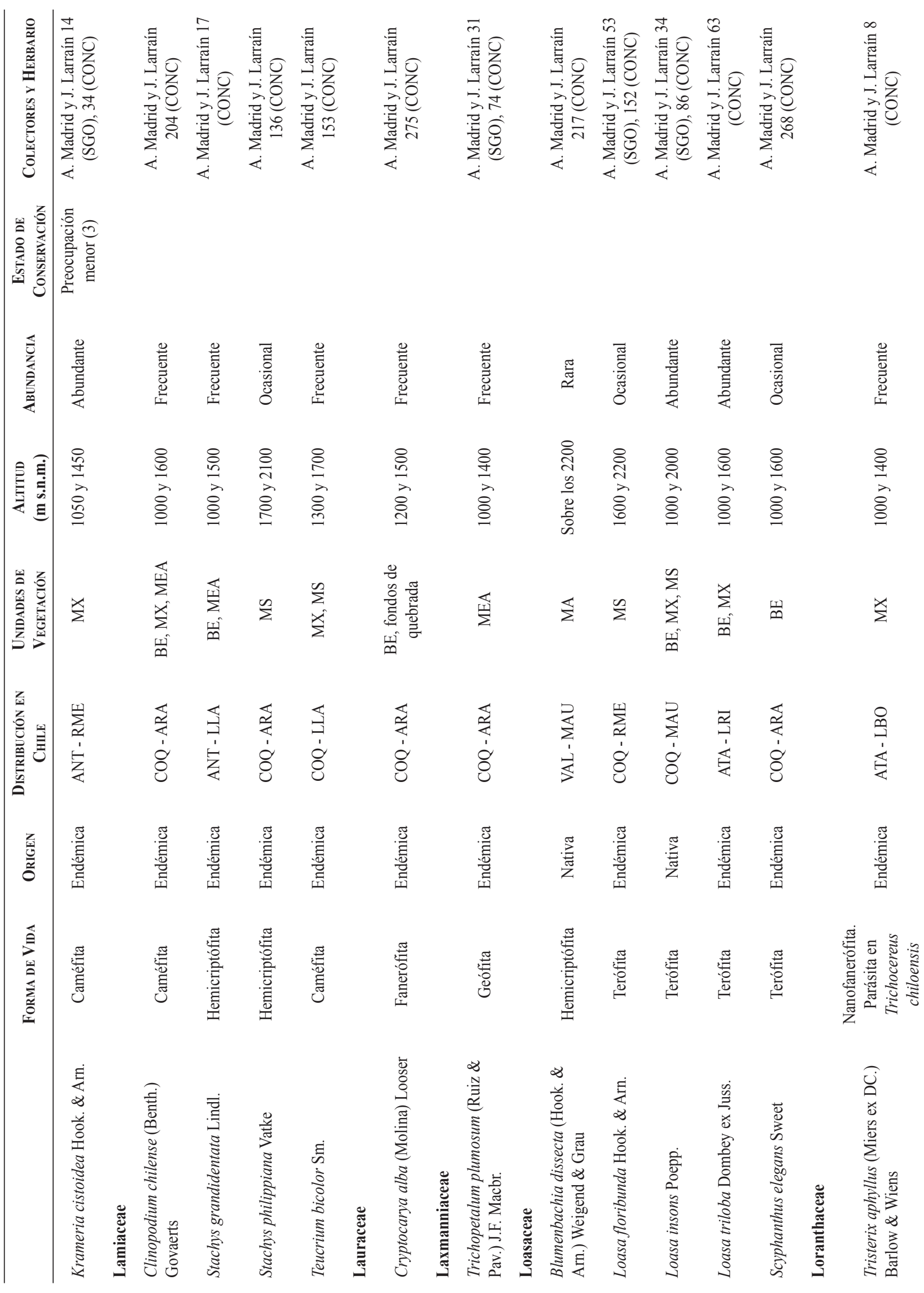




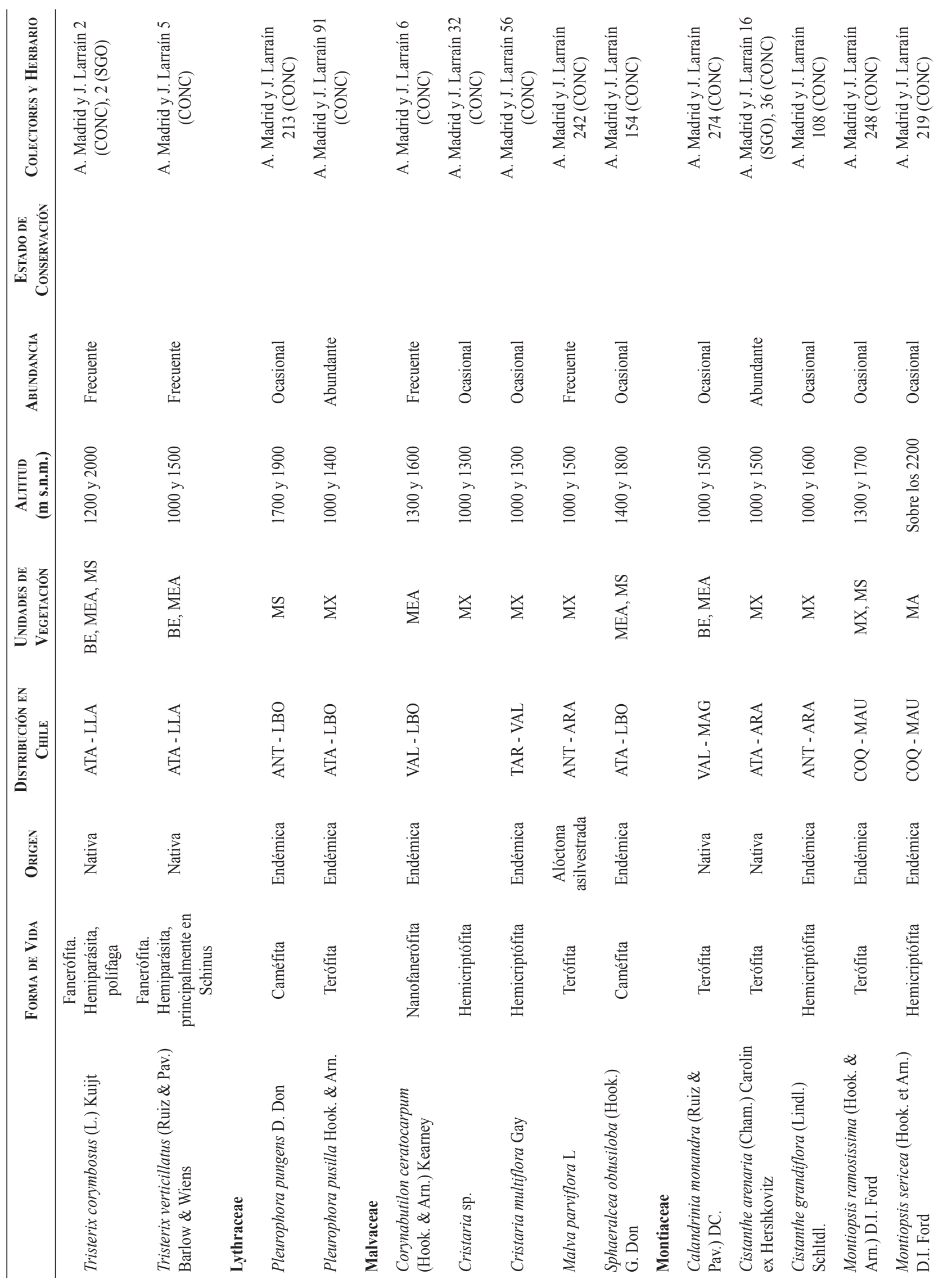




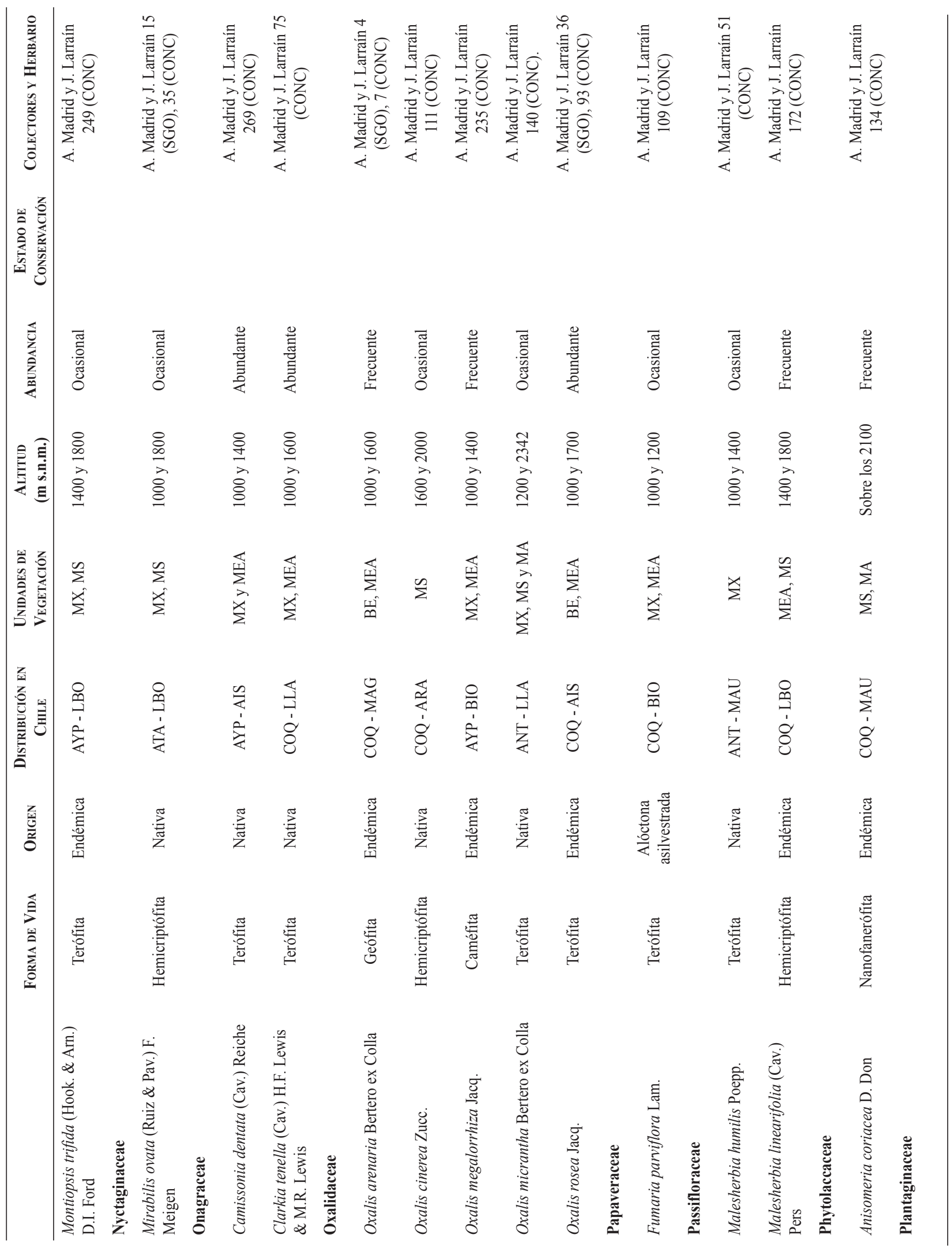




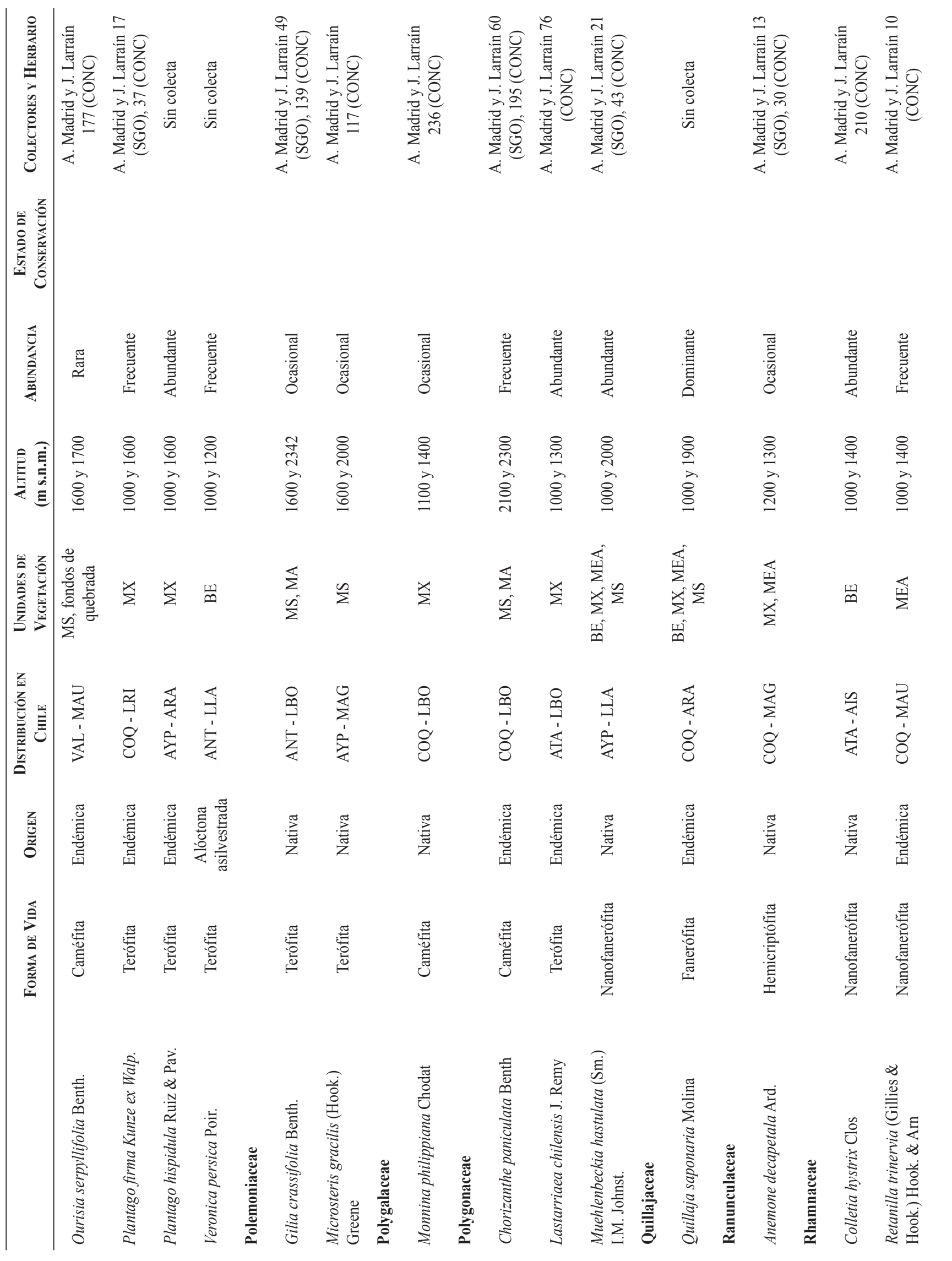




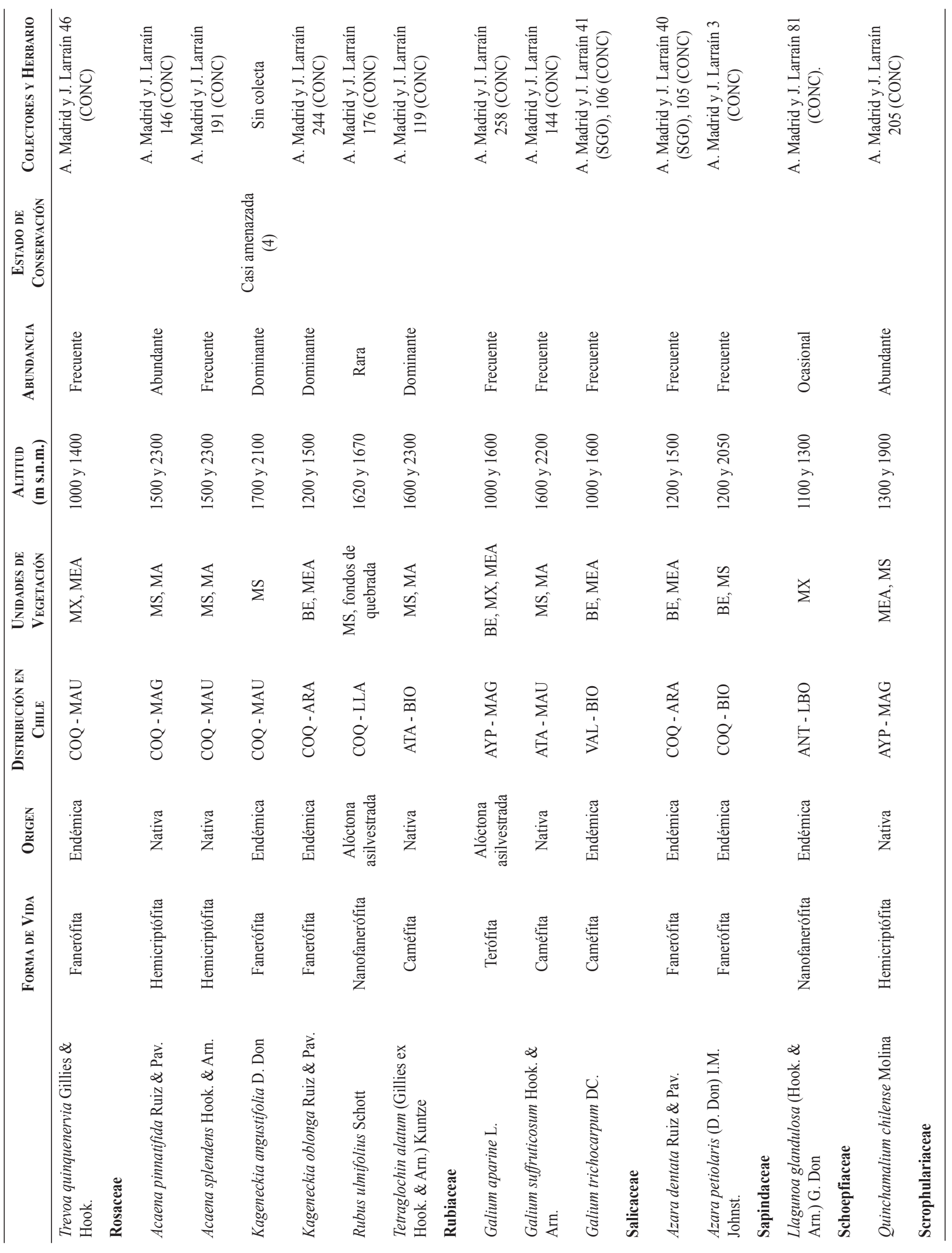




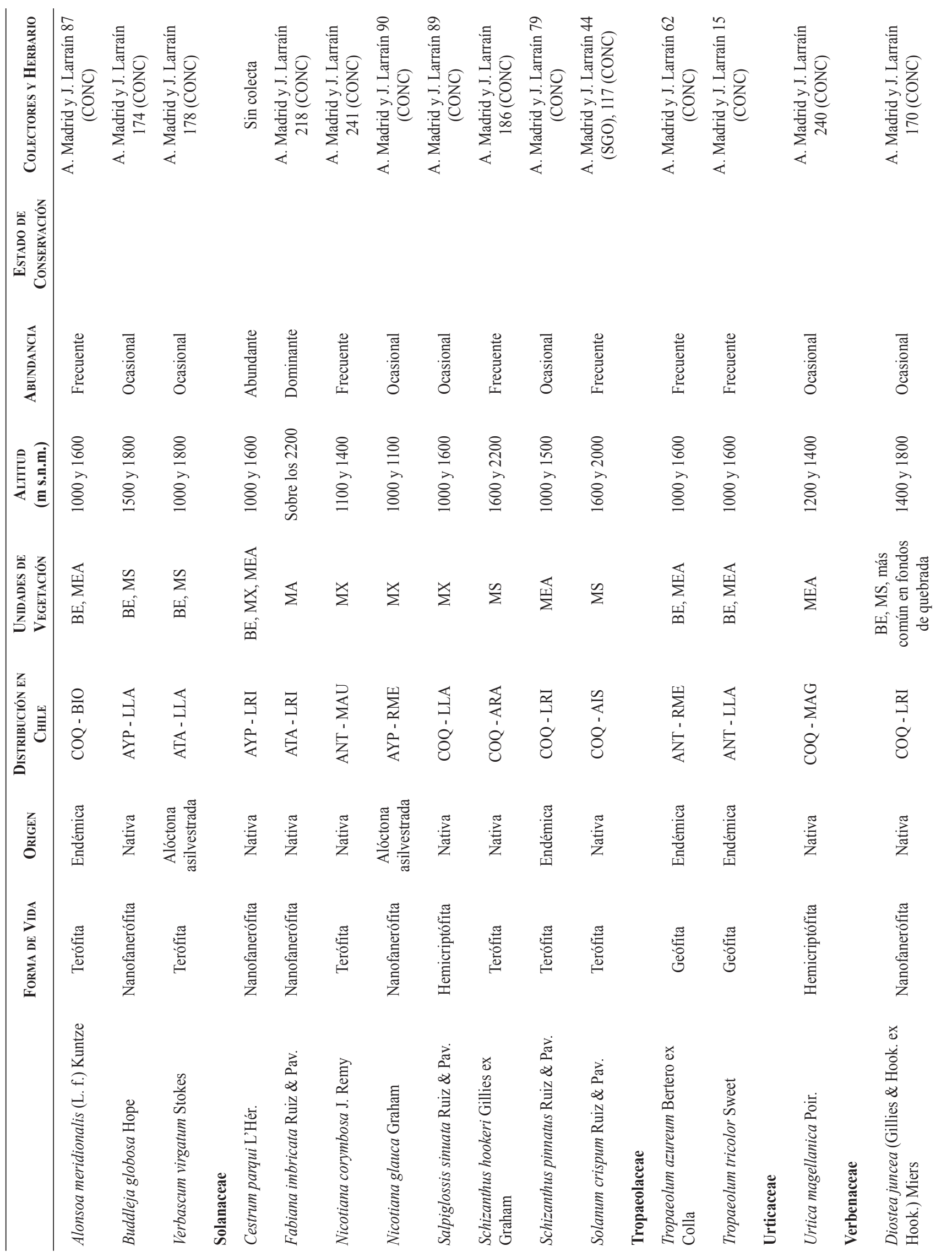




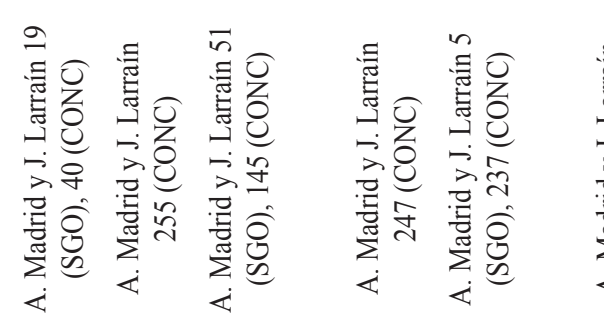$$
1
$$

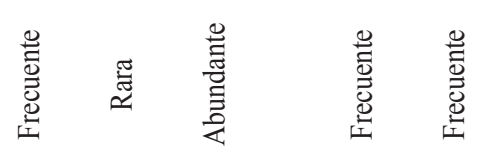

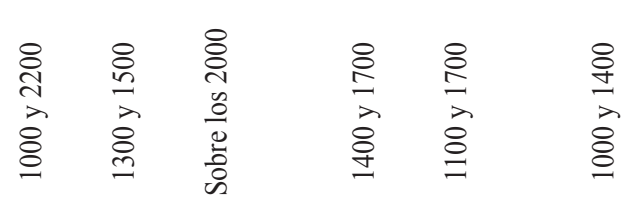

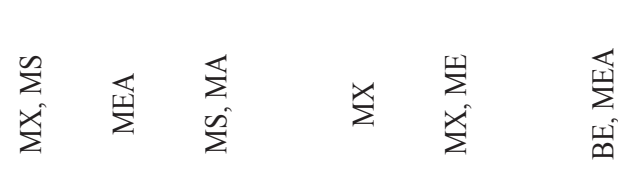

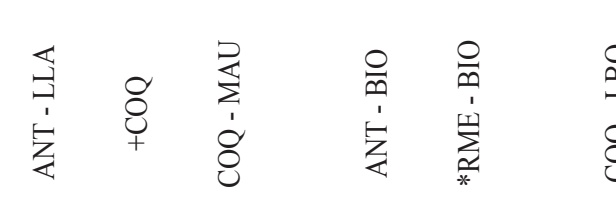

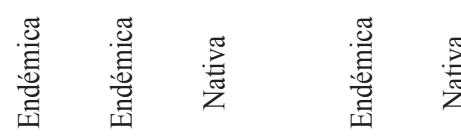

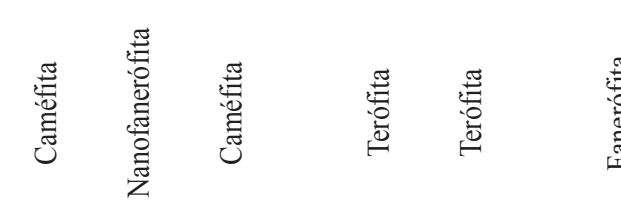

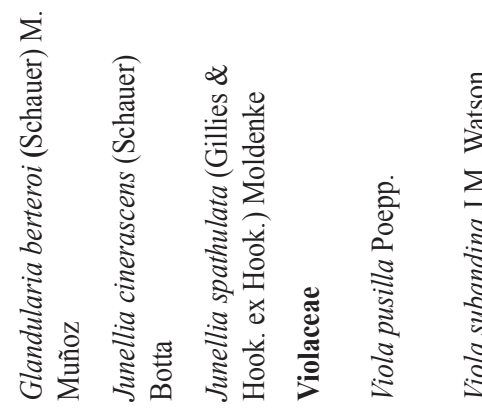

.ับ

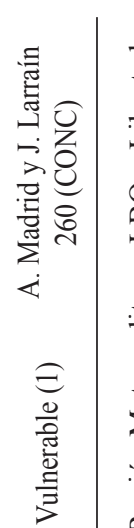

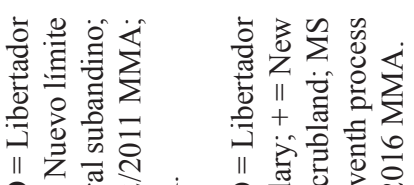

○॥

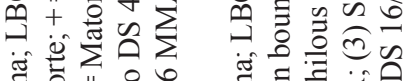

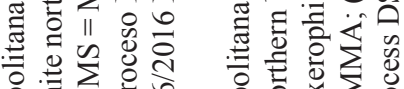

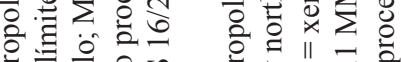

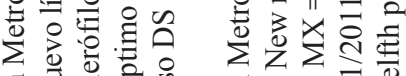

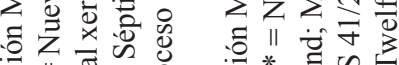

喿

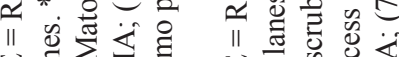

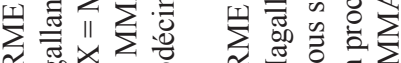

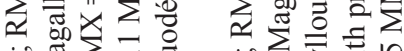

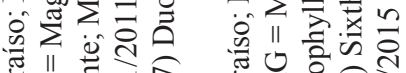

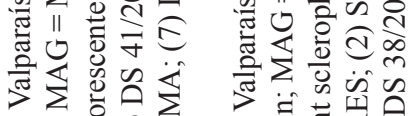

"I

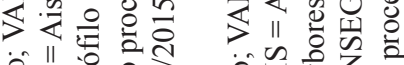

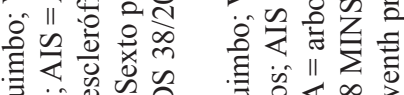

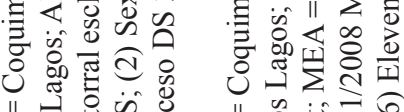

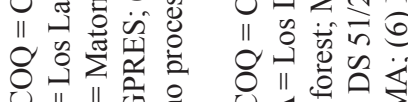

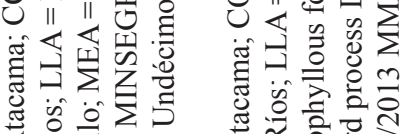

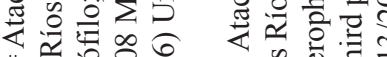

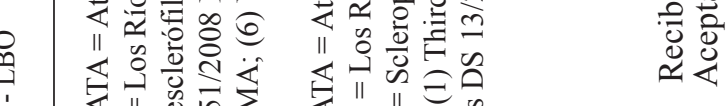

¿

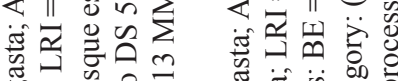

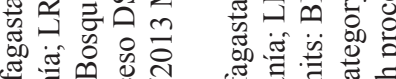

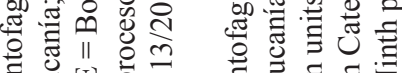

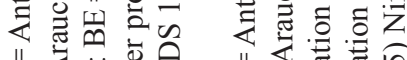

$\|$ 运岂

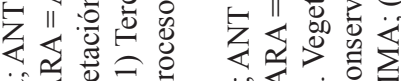

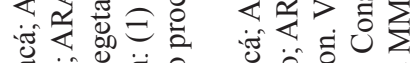

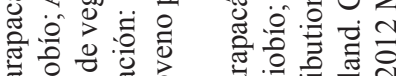

๘

\|\|"

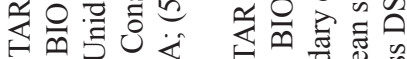

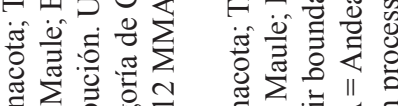

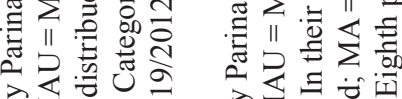

$\lambda \vec{z} 0 \Omega$

.

《I.

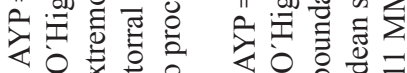

《०

o

宛芯芯芯导 